\title{
Adenomatous Polyposis Coli Regulates Oligodendroglial Development
}

\author{
Jordan Lang, Yoshiko Maeda, Peter Bannerman, Jie Xu, Makoto Horiuchi, David Pleasure, and Fuzheng Guo \\ Institute for Pediatric Regenerative Medicine, University of California, Davis, School of Medicine and Shriners Hospital, Sacramento, California 95817
}

The expression of the gut tumor suppressor gene adenomatous polyposis coli $(A p c)$ and its role in the oligodendroglial lineage are poorly understood. We found that immunoreactive APC is transiently induced in the oligodendroglial lineage during both normal myelination and remyelination following toxin-induced, genetic, or autoimmune demyelination murine models. Using the Cre/loxP system to conditionally ablate APC from the oligodendroglial lineage, we determined that APC enhances proliferation of oligodendroglial progenitor cells (OPCs) and is essential for oligodendrocyte differentiation in a cell-autonomous manner. Biallelic Apc disruption caused translocation of $\beta$-catenin into the nucleus and upregulated $\beta$-catenin-mediated Wnt signaling in early postnatal but not adult oligodendroglial lineage cells. The results of conditional ablation of Apc or Ctnnb1 (the gene encoding $\beta$-catenin) and of simultaneous conditional ablation of $A p c$ and $C t n n b 1$ revealed that $\beta$-catenin is dispensable for postnatal oligodendroglial differentiation, that $A p c$ one-allele deficiency is not sufficient to dysregulate $\beta$-catenin-mediated Wnt signaling in oligodendroglial lineage cells, and that APC regulates oligodendrocyte differentiation through $\beta$-catenin-independent, as well as $\beta$-catenin-dependent, mechanisms. Gene ontology analysis of microarray data suggested that the $\beta$-catenin-independent mechanism involves APC regulation of the cytoskeleton, a result compatible with established APC functions in neural precursors and with our observation that Apc-deleted OPCs develop fewer, shorter processes in vivo. Together, our data support the hypothesis that APC regulates oligodendrocyte differentiation through both $\beta$-catenin-dependent and additional $\beta$-catenin-independent mechanisms.

\section{Introduction}

Germ-line truncated mutations of the tumor suppressor gene, adenomatous polyposis coli ( $A p c, 15$ exons, encoding a $312 \mathrm{kDa}$ protein), cause familial adenomatous polyposis, and somatic Apc mutations are frequent in sporadic gut neoplasms. In colorectal cancers, APC regulates $\mathrm{Wnt} / \beta$-catenin signaling via its $\beta$-catenin domain, and cytoskeletal configuration via its $\beta$-catenin, microtubule, EB1, and DLG1-binding domains (Näthke, 2006).

In the CNS, in situ hybridization demonstrated a largely neuronal localization of Apc mRNA (Bhat et al., 1994), but immunohistochemistry (IHC) using a monoclonal antibody developed against an APC immunogen [clone CC1 (CC1)] suggested predominant expression of APC in oligodendrocytes (Bhat et al., 1996). This paradox was later resolved by proof that CC1, though a useful "marker" for oligodendrocytes, recognizes an antigen other than APC (Brakeman et al., 1999). This left unresolved, however, whether APC is expressed in the oligodendroglial lin-

Received July 19, 2012; revised Nov. 30, 2012; accepted Dec. 20, 2012.

Author contributions: D.P. and F.G. designed research; J.L., Y.M., P.B., J.X., M.H., and F.G. performed research; J.L., Y.M., P.B., J.X., M.H., D.P., and F.G. analyzed data; J.L., D.P., and F.G. wrote the paper.

This work was supported by National Institutes of Health Grant R01 NS025044, National Multiple Sclerosis Society Grant RG4397-A-5, the Shriners Hospitals for Children, and the California Institute for Regenerative Medicine.

Correspondence should be addressed to either David Pleasure or Fuzheng Guo, Institute for Pediatric Regenerative Medicine, University of California Davis and Shriners Hospitals for Children, Northern California, 2425 Stockton Boulevard, Sacramento, CA 95817, E-mail: david.pleasure@ucdmc.ucdavis.edu or fzguo@ucdavis.edu.

DOI:10.1523/JNEUROSCI.3467-12.2013

Copyright $\odot 2013$ the authors $\quad 0270-6474 / 13 / 333113-18 \$ 15.00 / 0$ eage and, if so, at what developmental stages and with what functional significance.

Prior reports indicated that APC in the CNS regulates process formation and extension by radial glia, astroglia, neurons, proliferation of neuroblasts, and trophic interactions between Bergmann glia and Purkinje cells (Yokota et al., 2009; Imura et al., 2010; Wang et al., 2011). A recent study (Fancy et al., 2009) demonstrated that oligodendroglial differentiation and remyelination are delayed in adult $A p c^{\text {min/+ }}$ mice ( $A p c$ multiple intestinal neoplasia, 1-allele truncated mutation of $A p c$, lacking $\beta$-catenin-binding domain) (Moser et al., 1993) following lysolecithin-induced demyelination, and suggested, but did not prove, that this delay was attributable to dysregulation of $\mathrm{Wnt} / \beta$ catenin signaling in these $A p c$-haploinsufficient mice. That study did not address several important questions. Does single-allele APC truncation lead to upregulation of $\mathrm{Wnt} / \beta$-catenin signaling in the CNS? Since axonal activity regulates oligodendroglial progenitor cell (OPC) differentiation (Barres and Raff, 1999), were the delays in oligodendrogenesis and remyelination secondary to axonal dysfunction elicited by the Apc mutation (Zhou et al., 2004; Chen et al., 2011; Wang et al., 2011), or does APC exert cell-autonomous effects on oligodendroglial differentiation?

Using an antibody specific to APC, we observed that immunoreactive APC is expressed transiently in the oligodendroglial lineage during normal oligodendroglial development and oligodendroglial regeneration, in sharp contrast to the pattern of oligodendrocyte marker CC1. We found that biallelic APC disruption decreases OPC proliferation and inhibits OPC process formation, and that APC is essential for oligodendrocyte differ- 
entiation through both $\beta$-catenin-dependent and $\beta$-cateninindependent mechanisms, the latter likely affecting the structure of the oligodendroglial cytoskeleton.

\section{Materials and Methods}

Animals. NG2 (Cspg4)-Cre (JAX stock \#008533) (Zhu et al., 2008), Apc ${ }^{\mathrm{min} /+}$ (JAX stock \#002020) (Moser et al., 1993), BAT-lacZ (Wnt/ $\beta$ catenin signaling reporter, JAX stock \#005317) (Maretto et al., 2003), Rosa-EYFP (JAX stock \#006148), Ctnnb1 $1^{\text {exon2-6flox/flox }}\left(C_{t n n b 1} 1^{\text {fl/fl }}\right.$, JAX stock \#004152) (Brault et al., 2001) were purchased from The Jackson Laboratory. Cnp-Cre (Lappe-Siefke et al., 2003), Olig2-Cre-ER ${ }^{\mathrm{T} 2}$ (Takebayashi et al., 2002), and ASPA ${ }^{\text {Nur7 }}$ mutant mice (Traka et al., 2008) were kindly provided by Klaus-Armin Nave (Max Planck Institute of Experimental Medicine) via Judith Grinspan (Children's Hospital of Philadelphia), Hirohide Takebayashi (Kumamoto University) via Chengji Zhou (University of California, Davis) and Brian Popko (University of Chicago), respectively. Apc-flox mice (National Cancer Institute strain \#01XAA, LoxP sites flanking exon 14) (Kuraguchi et al., 2006) were purchased from the National Cancer Institute. Upon Cre-mediated deletion of Apc exon 14, the transcription of Apc in these mice results in a shift in the normal reading frame, thus encoding a possible truncated 580 aa polypeptide that lacks central $\beta$-catenin-binding domain and C-terminal microtubule-binding, EB1-binding, and DLG1binding domains. These transgenic mice were bred to produce transgenic study mice and corresponding control mice. Both male and female mice were used in our study. All mice were maintained on the C57BL/6 background.

Tamoxifen and ethynyl deoxyuridine injection. For conditional gene deletion (either Apc or Ctnnb1 or both) by inducible Olig2-Cre-ER ${ }^{\mathrm{T} 2}$ (OCE), neonatal pups received one intraperitoneal tamoxifen injection (dose, $100 \mu \mathrm{g}$ of tamoxifen/g body weight) per day on postnatal day (P) 6 and P7. The spinal cord and forebrain were analyzed at different time points as indicated in the text and figure legends. Mice received a single intraperitoneal injection of ethynyl deoxyuridine (EdU, $100 \mu \mathrm{g} / \mathrm{g}$ body weight) $2 \mathrm{~h}$ before kill.

Primary OPC culture and differentiation. Primary mixed glial (MG) cultures were prepared from mouse and rat forebrains by methods modified from our previous reports (Itoh et al., 2002; Horiuchi et al., 2010). Forebrains were harvested between ages P0 and P2. The tissues were dissociated using the Papain Dissociation System (PDS) Kit (Worthington) supplemented with DNase I $(250 \mathrm{U} / \mathrm{ml})$ and D- $(+)$-glucose $(0.36 \%$; Sigma-Aldrich) for $90 \mathrm{~min}$ in a humidified incubator at $33^{\circ} \mathrm{C} / 10 \% \mathrm{CO}_{2}$. Next, the tissue was immersed in PDS Kit-Inhibitor solution $[10 \mathrm{mg} / \mathrm{ml}$ ovomucoid protease inhibitor, $10 \mathrm{mg} / \mathrm{ml}$ bovine serum albumin (BSA) and $125 \mathrm{U} / \mathrm{ml}$ DNase I in Dulbecco's PBS; Worthington]. Tissue chunks were triturated, and the cell suspension supernatant was collected. After centrifugation [220 relative centrifugal force, $15 \mathrm{~min}$ ], cells were plated on a poly-D-lysine (PDL)-coated (Sigma-Aldrich) $10 \mathrm{~cm}$ dish in medium containing $10 \%$ heat-inactivated fetal bovine serum, glutamax, and penicillin/streptomycin (P/S) in high-glucose DMEM (all Invitrogen). After $24 \mathrm{~h}$ in vitro, serum-free "growth medium" (GM) was added to stimulate OPC proliferation. GM consisted of seven parts N1 medium $(5 \mu \mathrm{g} / \mathrm{ml}$ insulin, $50 \mu \mathrm{g} / \mathrm{ml}$ transferrin, $100 \mu \mathrm{M}$ putrescine, $30 \mathrm{nM}$ sodium selenite, $20 \mathrm{~nm}$ progesterone, $10 \mathrm{ng} / \mathrm{ml}$ biotin; Sigma-Aldrich) and three parts B104 neuroblastoma-conditioned N1 medium together with P/S. The cultures were provided fresh GM at $72 \mathrm{~h}$ in vitro and, after $96 \mathrm{~h}$ total in vitro, the MG cultures were immunopanned to produce OPC-enriched cultures. Rat cultures were immunopanned according to our published methods (Itoh et al., 2002; Horiuchi et al., 2010). Before panning, mouse cultures were resuspended in "panning solution" $(0.1 \%$ BSA in N1 medium). Mouse cultures were negatively panned once with rat anti-Thy1.2 antibody (American Type Culture Collection, clone 30H12) and positively panned once with rabbit anti-NG2 antibody (Millipore, AB5320). OPC-enriched cultures were grown on PDL-coated plates. Rat OPCenriched cultures were expanded in GM with recombinant murine PDGF-A chain homodimer (PDGF-AA, $1 \mathrm{ng} / \mathrm{ml})$ and FGF2 $(5 \mathrm{ng} / \mathrm{ml})$ (Peprotech). Mouse OPC-enriched cultures were expanded in GM with PDGF-AA (2 ng/ml) and FGF2 (10 ng/ml), forskolin (50 $\mu \mathrm{M}$; Enzo Life
Sciences) (Horiuchi et al., 2010), and glutamax. To induce differentiation, the medium was switched to "differentiation medium," which consisted of $12.5 \mu \mathrm{g} / \mathrm{ml}$ insulin, $50 \mu \mathrm{g} / \mathrm{ml}$ transferrin, $100 \mu \mathrm{M}$ putrescine, 24 nм sodium selenite, $10 \mathrm{~nm}$ progesterone, $10 \mathrm{ng} / \mathrm{ml}$ biotin, $30 \mathrm{ng} / \mathrm{ml}$ 3,3',5-triiode-L-thyronine, $40 \mathrm{ng} / \mathrm{ml}$ L-thyrozine (all Sigma-Aldrich), glutamax, and 0.3\% D- $(+)$-glucose in F12/high-glucose DMEM, 1:1 medium (Invitrogen).

Remyelination models: myelin oligodendrocyte glycoprotein peptide 35-55 induced experimental autoimmune encephalomyelitis, ASPA Nur7 murine Canavan disease, and cuprizone-induced corpus callosum demyelination. Myelin oligodendrocyte glycoprotein peptide (MOG-peptide) 35-55 experimental autoimmune encephalomyelitis (EAE) was induced in 3-month-old C57BL/6 mice of both sexes (Guo et al., 2011, 2012). Four-month postnatal ASPA ${ }^{\text {Nur7 }}$ homozygous mutant male mice were analyzed; these mice showed demyelination and partial remyelination, together with microcyst formation, in forebrain and cerebellum (Traka et al., 2008). For cuprizone-induced demyelination, 2-month-old C57BL/6 mice of both sexes were maintained on $0.25 \%(\mathrm{w} / \mathrm{w})$ diet for 6 weeks, causing selective depletion of oligodendroglia in corpus callosum; following return to a normal diet, surviving OPCs proliferated, and differentiated into myelinating oligodendrocytes (Mason et al., 2004), with remyelination completed by 6 weeks thereafter (Kipp et al., 2009). The cuprizone-fed mice were killed at the end of 6 week cuprizone diet, or 4 or 6 weeks later.

Tissue preparation. Tissue processing and sectioning were conducted as described in our previous studies (Guo et al., 2009, 2010, 2011, 2012). Fourteen-micron-thick frozen sections were prepared for immunohistochemistry and mRNA in situ hybridization.

Primary antibodies. The primary antibodies used in this study were described in our previous studies (Guo et al., 2009, 2010, 2011, 2012) except for the following: APC [rabbit, Santa Cruz Biotechnology, \#sc896, 1:100 on IHC and immunocytochemistry (ICC), 1:1000 on Western blot (WB)], APC immunogen peptide (Santa Cruz Biotechnology, \#sc896P, specific to sc-896 APC antibody), CC1 (mouse, Calbiochem, \#OP80, 1:200 on IHC), DLG1 (rabbit, Thermo Scientific, \#PA1-741, 1:200 on paraffin section, 1:1000 on WB; mouse, BD PharMingen, \#610874, immunoprecipitation), $\beta$-catenin (mouse, BD PharMingen, \#610153, 1:1000 on WB, 1:200 on IHC), acetylated $\alpha$-tubulin (mouse, SigmaAldrich, \#T7451, 1:10,000 on WB, 1:200 on ICC), $\alpha$-tubulin (mouse, Invitrogen, \#A11126, 1:200 on ICC; rabbit, Cell Signaling Technology, \#2144, 1:1000 on WB), phosphorylated histone H3, PH3 (rabbit, Millipore, \#06-570, 1:200 on IHC), Ki67 (mouse, Vector, \#VP-K452, 1:100 on IHC), active caspase 3 (rabbit, Promega, \#G748A, 1:200 on IHC), $\beta$-galactosidase, $\beta$-gal (rabbit, Cappel, \#55978, 1:200 on IHC).

IHC and confocal microscopy. Immunostaining and confocal imaging were conducted according to our published protocol (Guo et al., 2009, 2010, 2011).

$m R N A$ in situ hybridization. Probe preparation and hybridization were performed as described in our previous study (Guo et al., 2012).

Coimmunoprecipitation. Rat OPC-enriched cultures were seeded at $1.8 \times 106$ cells per $75 \mathrm{~cm}^{2}$ PDL-coated culture flask, and differentiation was induced the next morning. At day two, cultures were rinsed with ice-cold PBS and extracted with coimmunoprecipitation (CoIP) lysis buffer containing $10 \mathrm{~mm}$ Tris buffer, pH 7.4, $140 \mathrm{~mm} \mathrm{NaCl}, 0.5 \%$ Nonidet P-40 (Igepal CA-630), 1 mм EDTA, 1 mm EGTA (all Sigma-Aldrich), complete protease inhibitor mixture (Roche), and PhosSTOP phosphatase inhibitor mixture (Roche). The cell lysate was gently homogenized by P1000 micropipetting 30 times and was incubated on ice for $15 \mathrm{~min}$. Then, the lysate was centrifuged at $10,000 \mathrm{rpm}$ for $10 \mathrm{~min}$ at $4^{\circ} \mathrm{C}$. The supernatant was collected and the protein concentration was adjusted to $\sim 1 \mathrm{mg} / \mathrm{ml}$, and some adjusted lysate was set aside for Western blot analysis ("Input" sample). For immunoprecipitation (IP), protein G magnetic beads (New England Biolabs) were used, and the samples were precleared and immunoprecipitated following the manufacturer's protocol except using CoIP lysis buffer. Antibodies used for IP included control IgG (eBioscience), anti-APC (Millipore), and anti-Dlg1 (BD PharMingen) antibodies. The bead-IP complexes were eluted with $\mathrm{Nu}$ PAGE lithium dodecylsulfate (LDS) sample buffer with reducing agent (Invitrogen) and the IP samples were analyzed for CoIP by Western blot. 
Protein extraction and Western blots. Protein extractions were performed using radioimmunoprecipitation analysis lysis buffer system with protease inhibitors (Santa Cruz Biotechnology, \#sc-24948). Protein concentrations were measured using BCA kits (Thermo Scientific, \#23235). NuPAGE LDS sample buffer with reducing agent (Invitrogen) was used to denature $10 \mu \mathrm{g}$ of protein extract. For analysis of APC expression and for CoIP experiments, samples were separated by electrophoresis in NuPAGE Novex 3-8\% gels. For analysis of tubulin acetylation, 4-12\% Bis-Tris gels were used (Invitrogen). Electrophoresed proteins were transferred to nitrocellulose membranes (Invitrogen). Membranes were blotted and imaged using the LI-COR Infrared scanner system (LI-COR Biosciences) according to the manufacturer's protocol with LI-COR Blocking Buffer and with the secondary antibodies goat anti-rabbit IRDye $800 \mathrm{CW}$ and goat anti-mouse IRDye 680RD, each diluted 1:10,000 (LI-COR Biosciences). LI-COR Image Studio 2.0 software was used to analyze band-signal intensity with subtraction of the median background outside the band selection perimeter.

RNA isolation and quantitative real-time PCR. Total RNA extraction, cDNA preparation and quantitative real-time PCR (qRT-PCR) were performed as described in a previous study (Guo et al., 2012). The copy number of each gene of interest was normalized to that of internal control glyceraldehyde-3-phosphate dehydogenase (GADPH), and, for analysis, the expression level of each gene in wild-type mice was set at a value of 1 .

The primers for qRT-PCR were obtained mainly from the PrimerBank at Harvard University (http://pga.mgh.harvard.edu/primerbank/). The primer sets were as follows (sequences are aligned from $5^{\prime}$ to $3^{\prime}$, forward/ reverse primers): Mbp (ACACGAGAACTACCCATTATGGC/CCAGCTA AATCTGCTGAGGGA), Cnp (TTTACCCGCAAAAGCCACACA/CACC GTGTCCTCATCTTGAAG),Plp(CCAGAATGTATGGTGTTCTCCC/GG CCCATGAGTTTAAGGACG), GADPH(AGGTCGGTGTGAACGGATTT G/TGTAGACCATGTAGTTGAGGTCA), Tcf712 (TCACGCCTCTCATC ACGTACA/GTGCGGAGGTGGATTTCCC), Axin2 (AACCTATGCCCG TTTCCTCTA/GAGTGTAAAGACTTGGTCCACC), Naked1 (CAGCTTG CTGCATACCATCTAT/GTTGAAAAGGACGCTCCTCTTA), Notum (G GACAGCTTTATGGCGCAAG/TCACCGACGTGTTCAGCAG), Dlg1 (C AACACAGACAGCTTAGAGACAC/ACCCGAATTTCCCCTTTCAAG), Casr (AGCAGGTGACCTTCGATGAGT/ACTTCCTTGAACACAATGGA GC), Kif19a (TCTATGTTCGGACCCTCAATGA/ATCACCCCTTTGGA GTCTTCC), Sox10 (ACACCTTGGGACACGGTTTTC/TAGGTCTTGTT CCTCGGCCAT), Rnf122 (CACCCATTCCAGTGGTGTAAC/GCACAG GTCCCATAGAGCTG), MAG (CTGCCGCTGTTTTGGATAATGA/CAT CGGGGAAGTCGAAACGG), Fyn (ACCTCCATCCCGAACTACAAC/CG CCACAAACAGTGTCACTC), CXCR4 (GAAGTGGGGTCTGGAGACTA T/TTGCCGACTATGCCAGTCAAG), Cx3cl1 (ACGAAATGCGAAATCA TGTGC/CTGTGTCGTCTCCAGGACAA), Ctnnb1 (ATGGAGCCGGAC AGAAAAGC/CTTGCCACTCAGGGAAGGA), cyclinD1 (GCGTACCCTG ACACCAATCTC/CTCCTCTTCGCACTTCTGCTC).

Microarray and gene ontology analysis. Total RNA was isolated from the cervical spinal cord by RNeasy minikits (Qiagen, see RNA isolation and quantitative real-time PCR). RNA concentrations were measured by NanoDrop spectrometry, and RNA integrity was evaluated with the Agilent 2100 Bioanalyzer. Microarray experiments and analysis were performed by the University of California Davis Cancer Center Genomics and Expression Resource. Genome-wide expression profiling using Mouse Gene 1.0 ST GeneChip arrays (Mouse Gene 1.0 ST, Affymetrix) was performed according to the manufacturer's protocols. Data analysis was performed with the GeneSpring GX (version 11) software suite (Agilent Technologies). Briefly, exon RMA 16 was used for probe summarization and normalization of background-adjusted, normalized, and log-transformed perfect-match probe intensity values from the .cel raw data files. Comparison analysis was then performed to identify genes that were differentially expressed in the different treatment groups. Criteria for the selection of genes exhibiting significant expression changes included an average fold change of $\geq 1.2$ between groups and $p$ values of $\leq 0.05$ while adjusting for multiple testing corrections using the Benjamini-Hochberg false discovery rate (FDR). Potential functions and pathways affected by the $A p c$ deletion were queried by organizing the genes based upon gene ontology (GO) annotations for biological process using the Database for Annotation, Visualization and Integrated Discovery (DAVID) (Huang da et al., 2009a,b).

Sholl analysis. Sholl analysis (Rajasekharan et al., 2009) of OPC processes was conducted by the Sholl ImageJ plugin, using $10 \mu \mathrm{m}$ optical thickness confocal images with a $100 \times$ objective. Parameter settings were as follows: starting radius, $10 \mu \mathrm{m}$; ending radius, $50 \mu \mathrm{m}$; radius step size, $10 \mu \mathrm{m}$. The number of intersections at each radius circle was used to compare wild-type and Apc KO OPCs.

Data collection. Mean intensities of myelin basic protein (MBP) immunostaining were measured by National Institutes of Health Image software. Cell number per section was calculated by counting all markerpositive cells in $14-\mu \mathrm{m}$-thick frozen section under a $10 \times$ objective. Cell density (cell number per $\mathrm{mm}^{2}$ ) was calculated by dividing total cell number by the total area counted. At least four $40 \times$ confocal projection images (with $10 \mu \mathrm{m}$ optical depth using confocal $z$-stack) from each 14- $\mu \mathrm{m}$-thick frozen section were counted, and at least three frozen sections from each animal and at least three animals from each group were counted. Axons in the corticospinal tract were counted using ImageJ software as previously described (Soulika et al., 2009; Guo et al., 2012).

Statistics. All quantification data in this study are expressed as means \pm SD. Statistics were conducted using GraphPad Prism 5. Two-tail unpaired Student's $t$ tests were used to compare two-group data, and oneway ANOVA with Bonferroni post-test was used to compare three-group data $\left({ }^{*} p<0.05,{ }^{* *} p<0.01,{ }^{* *} p<0.001\right.$; ns, not significant $)$.

\section{Results}

APC is transiently expressed in oligodendroglial lineage cells during normal development

We used a well characterized APC antibody (sc-896, Santa Cruz Biotechnology) (Sasaki et al., 2000; Jimbo et al., 2002; Wen et al., 2004; Mili et al., 2008) to study the expression of APC in oligodendroglial lineage cells. First, we used peptide-antibody preabsorptions to verify the specificity of the sc-896 antibody for APC. Consistent with a previous publication (Imura et al., 2010), APC was abundantly expressed in the molecular layer and dentate gyrus in the hippocampus (Fig. 1A), and this immunostaining was abolished when APC antibody was preincubated with the APC peptide (sc-896P, Santa Cruz Biotechnology) (Fig. 1 B). Second, gene knock-out $(\mathrm{KO})$ experiment also proved the specificity of the APC antibody we used (Fig. 2, compare A1, B2).

By double IHC with APC and CC1 antibodies, we showed that in the adult neocortex, the immunostaining pattern of APC was completely different from that of CC1 (Fig. 1C). APC was expressed in neurons (Fig. 1C, arrowheads) (Zhou et al., 2004), whereas $\mathrm{CC} 1$ was expressed in oligodendrocytes (Fig. 1C, arrows). These data confirmed that immunohistochemistry by CC1, though useful for identifying oligodendroglia (Bhat et al., 1996), does not reflect endogenous APC expression.

Is APC expressed in oligodendroglial lineage cells? We found that immunoreactive APC was not detectable in murine spinal cord white matter (WM) until embryonic day 18.5 (Fig. $1 D, E$ ), transiently peaked during active myelination, and was markedly downregulated in the adult (Fig. $1 F-H)$. This pattern of APC expression was in sharp contrast to the temporal patterns of CC1 immunostaining (Fig. 1I). Double IHC identified $\mathrm{APC}^{+}$cells in $\mathrm{WM}$ as Sox $10^{+}$(a panoligodendroglial lineage cell marker) oligodendroglial lineage (Fig. $1 J$ ) rather than $\mathrm{GFAP}^{+}$(an astrocyte marker) astrocytic lineage (data not shown). APC immunoreactivity was barely detectable in $\mathrm{NG} 2{ }^{+} \mathrm{OPCs}$ (data not shown), and substantially upregulated in $\mathrm{CC}^{+}$oligodendrocytes (Fig. $1 F-$ $H$ ). Interestingly, virtually all $\mathrm{APC}^{+}$oligodendroglial cells were immunopositive for the Wnt $/ \beta$-catenin signaling effector Tcf7l2, and virtually all Tcf7l2 cells expressed immunoreactive APC, independent of mouse age (Fig. $1 \mathrm{~K}$ ). Consistent with these in vivo results, APC protein was detected at a very low level in highly 

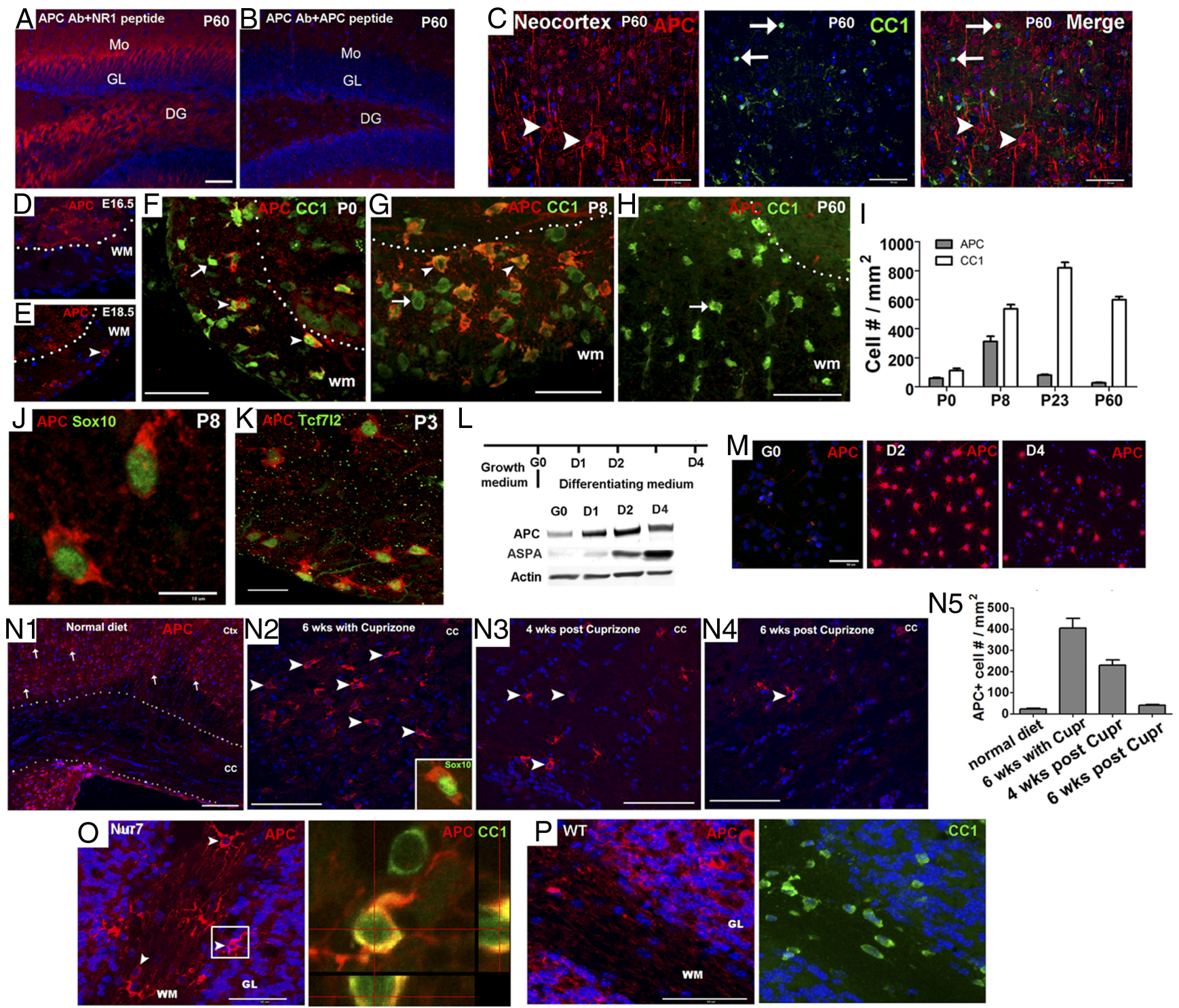

Figure 1. APC is transiently expressed in oligodendroglial lineage cells during normal development and after CNS demyelination. $\boldsymbol{A}-\boldsymbol{B}$, Peptide-antibody preabsorption experiment showing specificity of the APC antibody (\#sc-896) by IHC in the hippocampus. Mo, molecular layer of hippocampus; GL, granular layer of hippocampus; DG, dentate gyrus of hippocampus. C, Double IHC of APC and $\mathrm{CC} 1$ in the adult P60 neocortex. Note that APC stains cells with characteristic cortical neuron morphology (arrowhead), whereas CC1 stains small oligodendrocytes (arrows). D-H, Transient expression of APC in spinal cord and its colocalization with oligodendrocyte marker $C\left(1\right.$. $\boldsymbol{E}$, arrowhead, $\mathrm{APC}{ }^{+}$cell. $\boldsymbol{F}, \mathbf{G}$, arrowheads, $\mathrm{APC}^{+} \mathrm{CC} 1^{+}$cells. $\boldsymbol{F}-\boldsymbol{H}$, arrows, $\mathrm{APC}{ }^{-} \mathrm{CC} 1^{+}$cells. $\boldsymbol{I}$, Densities of $\mathrm{APC}^{+}$and $\mathrm{CC}^{+}$cells in the WM of spinal cord at different ages ( $n=3$ in each group). J, Double IHC of APC and panoligodendroglial marker Sox 10. $K, \mathrm{APC}^{+}$cells were positive for Tcf 72 , an essential activator of Wnt/ $\beta$-catenin signaling pathway in oligodendroglial lineage cells (Fancy et al., 2009). $L$, Experimental design for primary OPC culture and differentiation (top) and Western blot showing APC protein was low in purified OPCS (G0) and was upregulated in differentiating oligodendrocytes (D1, D2, and D4) (bottom). Note that mature oligodendrocyte marker ASPA (Traka et al., 2008) was essentially absent in OPCs on G0. M, Immunocytochemistry depicting the APC expression in OPCs on G0 and in differentiating oligodendrocytes on D2 and D4 in vitro. N1-N4, APC ${ }^{+}$ cells in the corpus callosum of mice on a normal diet (N1), 6 weeks on a cuprizone diet (N2), 4 weeks postcuprizone (N3), and 6 weeks postcuprizone (N4). Arrows in $N 1$ indicate APC ${ }^{+}$neurons in the cortex and arrowheads in $\mathbf{N 2 - N 4}$ point to $\mathrm{APC}^{+}$cells in corpus callosum. Insert in $\mathbf{N 2}$ showing APC ${ }^{+}$cells colabeled with oligodendroglial lineage marker Sox10. N5, Quantification of APC ${ }^{+}$ cells in corpus callosum ( $n=4$ in normal diet group, $n=3$ in other groups). $\mathbf{0}-\mathbf{P}, \mathrm{APC}^{+}$cell (arrowheads) in the cerebellar WM of ASPA ${ }^{\text {nur7 }}$ homozygous mutant and ASPA WT mice. Boxed area in $\mathbf{O}$ was showing in orthogonal view (right) colabeling with CC1. Scale bars: all except $J, K, 50 \mu \mathrm{m} ; \boldsymbol{J}, \boldsymbol{K}, 10 \mu \mathrm{m}$.

purified rodent primary OPC cultures (Horiuchi et al., 2010) (Fig. $1 L$, first lane; Fig. $1 M$, left), and was substantially upregulated as they differentiated to oligodendrocytes (Fig. $1 L, M$ ). Thus, both in vivo and in vitro data indicated that (1) APC expression is low at the early OPC stage and upregulated upon differentiation, and (2) APC expression in the oligodendroglial lineage is cell-autonomously regulated. Together, our study demonstrates that immunoreactive APC is transiently expressed in oligodendroglial lineage cells during normal oligodendrocyte development and myelination.
APC is transiently reinduced in oligodendroglial lineage cells after CNS injury

The transient expression of APC during normal oligodendroglial myelination prompted us to investigate whether APC is reexpressed during remyelination after CNS injury. In wild-type adult mice maintained on a normal diet, $\mathrm{APC}^{+}$cells were barely detectable in corpus callosum (Fig. 1N1), but $\mathrm{APC}^{+}$cells had substantially increased by 6 weeks on a cuprizone diet (Fig. $1 N 2, N 5$ ), when oligodendrocyte differentiation was active (Kipp et al., 2009), and then markedly decreased by 6 weeks postwith- 

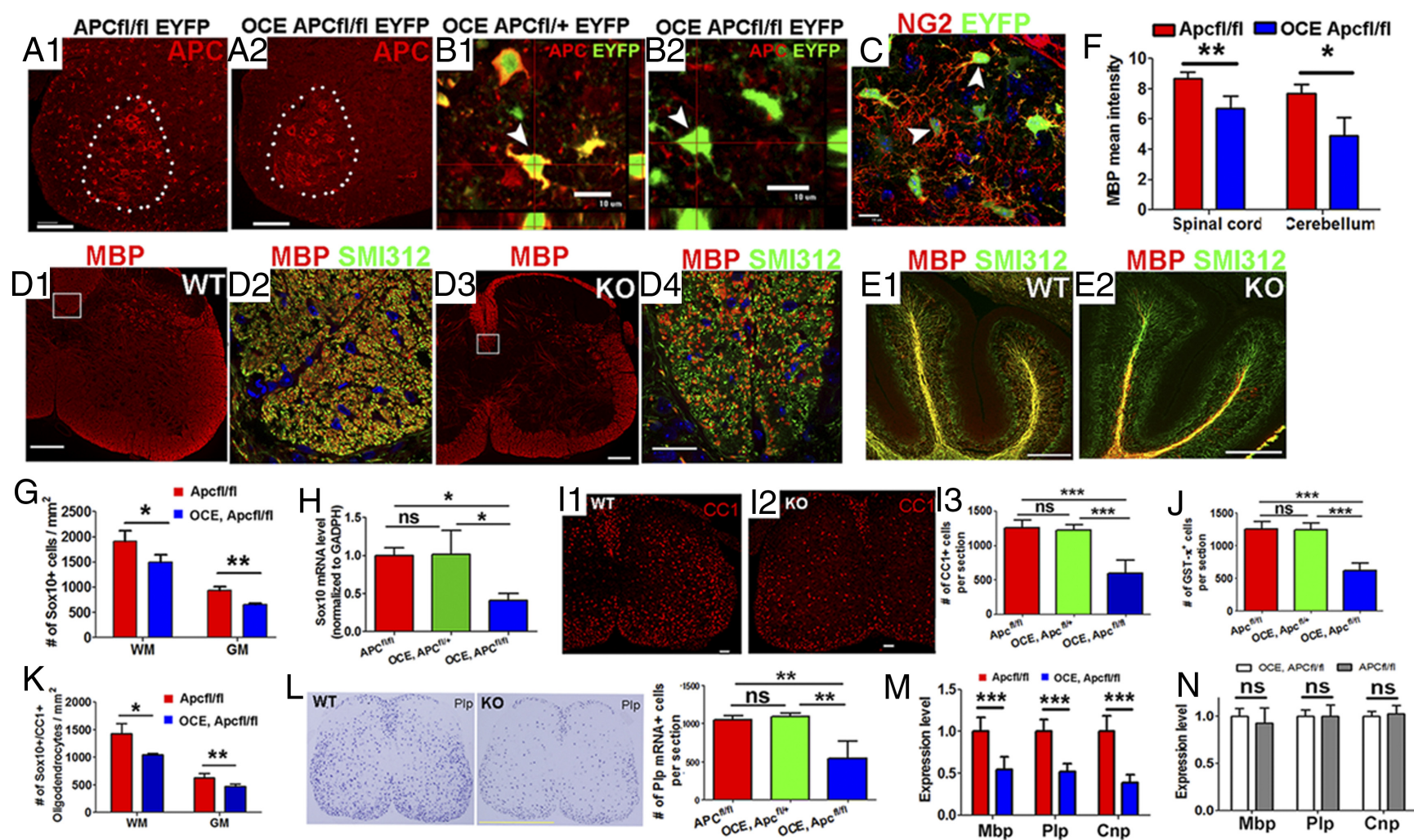

Figure 2. Apc disruption results in hypomyelination and inhibition of oligodendrocyte differentiation. Tamoxifen was injected in $0 C E / A p c$ fl/fl pups and littermates at P6 and P7 (see Materials and Methods) and CNS tissues were analyzed as indicated. A1, A2, APC staining in P14 OCE/Apc ${ }^{\mathrm{f} / / f 1}$, EYFP (KO), and Apc ${ }^{\mathrm{f} / / f 1}$, EYFP (WT) mice showing most APC ${ }^{+}$cells in the spinal WM were absent in K0 mice. Dotted areas delineate APC ${ }^{+}$motor neurons in the ventral horn. B1, B2, EYFP expression as a surrogate for APC disruption. C, EYFP expression in NG2 ${ }^{+}$OPCs in the spinal cord of OCE/ApC $C^{f / / f 1}$, EYFP mice on P8. D1-E2, MBP (myelin) and SMI312 (axons) double IHC showing hypomyelination in spinal cord (D1-D4) and cerebellar WM (E1, E2) at the level of confocal microscopy on P14. Boxed areas in $\mathbf{D 1}$ and $\mathbf{D 3}$ (corticospinal tract) are shown at higher power in $\mathbf{D 2}$ and $\mathbf{D 4}$, respectively. Note many SMI312 ${ }^{+} / \mathrm{MBP}^{-}$unmyelinated axons in K0 (compare $\mathbf{D 4}$ with $\mathbf{D 2}$ ). $\boldsymbol{F}$, Quantifications of MBP mean density ( $n=4$ spinal cord, $n=3$ cerebellum) in spinal cord and cerebellum. G, Densities of Sox $10^{+}$oligodendroglial lineage cells in WM and GM of spinal cord ( $n=$ 10 in WT, $n=7$ in KO). $\boldsymbol{H}$, MRNA levels of Sox10 in P14 Apc WT (Apc $\left.{ }^{\mathrm{fl} / \mathrm{fl}}, n=10\right)$, one-allele KO (OCE/Apc $\left.{ }^{\mathrm{fl} /+}, n=4\right)$, and two-allele KO (OCE, Apc fl/fl $\left.n=7\right)$ spinal cord. I1-I3, Representative confocal images and quantification of CC1 immunostaining on P14 spinal cord ( $n=10,4$, and 7, respectively).J, GST- $\pi^{+}$oligodendrocytes per section in each genotype of P14 spinal cord ( $n=10$, 4, and 7, respectively). $K$, Densities of Sox $10^{+} / \mathrm{CC}^{+}$oligodendrocytes in the WM and GM of P14 spinal cord in $A p c^{\mathrm{fl} / f l}(n=10)$ and $0 \mathrm{CE} / A p c^{\mathrm{fl} / f l}(n=7)$ mice. $L$, Representative images showing

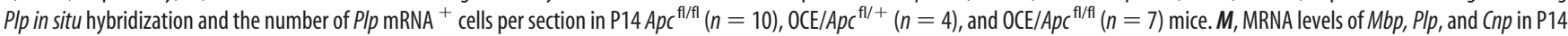

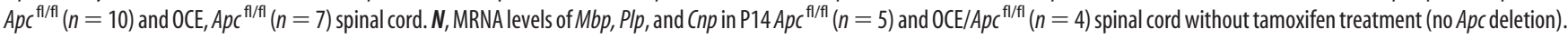
Scale bars: A1, A2, D1, D3, E1, E2, I1, I2, $50 \mu \mathrm{m} ; \boldsymbol{B} 1-C, D 4,10 \mu \mathrm{m} ; L, 500 \mu \mathrm{m}$.

drawal of cuprizone diet (Fig. 1N4,N5), when remyelination was completed (Kipp et al., 2009). In 4-month-postnatal ASPA ${ }^{\text {Nur7 }}$ mutant mice, an animal model of Canavan disease, in which the lack of oligodendroglial aspartoacylase (ASPA) causes continuous demyelinative and remyelinative activity in cerebellum (Traka et al., 2008), $\mathrm{APC}^{+}$cells were significantly increased in the cerebellar WM of ASPA $^{\text {Nur7 }}$ (Fig. 1O), in sharp contrast to ASPA wild-type littermate controls, in which few $\mathrm{APC}^{+}$cells were observed in cerebellar WM (Fig. 1P) $(34 \pm 11$ in WT, $155 \pm 43$ in ASPA $\left.^{\text {Nur7 }}, n=3, p<0.01\right)$. Thirty-five days after induction of MOG-peptide EAE (Soulika et al., 2009; Guo et al., 2012), APC ${ }^{+}$ cell numbers were significantly higher in spinal cord WM than in control mice given complete Freund's adjuvant (CFA) without MOG peptide $(32 \pm 12$ in CFA, $103 \pm 48$ in MOG, $n=4, p<$ $0.05)$. These increases in numbers of CNS APC ${ }^{+}$cells in toxininduced, genetic, and autoimmune demyelination/remyelination models suggest that APC reinduction is a common feature of remyelination after CNS injury.

Loss of oligodendroglial APC results in hypomyelination To investigate the role of APC in oligodendroglial differentiation, we bred Cnp-Cre mice (Lappe-Siefke et al., 2003) with Apc-floxed (Kuraguchi et al., 2006) mice to conditionally ablate APC expres- sion from the $\mathrm{Cnp}^{+}$OPCs and oligodendrocytes. Most Cnp-Cre/ $A p c^{\mathrm{f} / \mathrm{fl}}$ mice died within $24 \mathrm{~h}$ after birth, and the remaining mice died before weaning. Using the Cre reporter transgene RosaEYFP, we found that enhanced yellow fluorescent protein (EYFP) was expressed abundantly in lung, heart, and thymus, as well as in cortical neurons and spinal cord motor neurons (data not shown) at P1; we suspect that the early death of the Cnp-Cre/ $A p c^{\mathrm{f} / \mathrm{fl}}$ mice was due to the deletion of Apc's critical functions in these visceral organs and/or neurons (Gounari et al., 2005; Kuraguchi et al., 2006; Qian et al., 2008; Li et al., 2010). We demonstrated that the number of $\mathrm{APC}^{+}$cells in the WM of spinal cord at P7 was $\sim 30 \%$ less in Cnp-Cre/Apc $c^{\mathrm{fl} / \mathrm{fl}}$ mice than that in $A p c^{\mathrm{f} / \mathrm{fl}}$ control mice, and that the number of $P l p^{+}$oligodendrocytes per section (14 $\mu \mathrm{m}$ thick, here and hereafter) by mRNA in situ hybridization was significantly decreased in the Cnp-Cre/ $A p c^{\mathrm{f} / \mathrm{fl}}$ mice $\left(1097 \pm 80 A p c^{\mathrm{f} / \mathrm{fl}}, 834 \pm 67 \mathrm{Cnp}\right.$-Cre/Apc $c^{\mathrm{f} / \mathrm{fl}}$ per section on P14, $p<0.01, n=4$ ), indicating that oligodendrocyte differentiation is inhibited upon Apc disruption.

To further examine the cell-autonomous role of APC in postnatal oligodendroglial lineage cells, we crossed tamoxifeninducible OCE (Takebayashi et al., 2002) with Apc-floxed (Kuraguchi et al., 2006) mice and administered tamoxifen on P6 and P7 (see Materials and Methods). As shown in Figure 2A1,A2, 
this resulted in the loss of most $\mathrm{APC}^{+}$cells in both spinal cord $\mathrm{WM}$ and GM, whereas APC expression in motor neurons within ventral horn (Fig. 2A1, A2, dotted areas) was intact, thus demonstrating the specificity of $A p c$ deletion in Olig2 ${ }^{+}$OPCs and their progeny. Using EYFP expression to report Cre-mediated $A p c^{\mathrm{fl} / \mathrm{fl}}$ recombination (Fig. 2B1,B2, arrowheads) (Guo et al., 2012), we determined that $47 \pm 5 \%$ of Sox $10^{+}$oligodendroglial lineage cells were $\mathrm{EYFP}^{+}, 52 \pm 8 \%$ of NG2 ${ }^{+} \mathrm{OPCs}^{+}$were $\mathrm{EYFP}^{+}$(Fig. $2 \mathrm{C}$, arrowheads), and $75 \pm 9 \%$ of $\mathrm{EYFP}^{+}$cells were $\mathrm{NG}^{+}$OPCs on P8, thus indicating that approximately half of oligodendroglial lineage cells were $A p c$-deficient, and that most $A p c$-deficient cells were initially OPCs. Compared with $A p c^{\mathrm{fl} / \mathrm{fl}}$ control mice, the mean intensity of $\mathrm{MBP}^{+}$myelin fibers was significantly lower in $\mathrm{OCE} / A p c^{\mathrm{fl} / \mathrm{fl}} A p c \mathrm{KO}$ mice in spinal cord (Fig. 2D1,D3,F), cerebellum (Fig. 2E1,E2,F), and forebrain (data not shown). While numbers of SMI312 ${ }^{+}$(panaxonal marker) axonal fibers were similar (Fig. 2D2,D4), numbers of $\mathrm{SMI}_{3} 12^{+} / \mathrm{MBP}^{-}$unmyelinated axons in corticospinal tract were significantly higher in OCE $/ A p c^{\mathrm{fl} / f \mathrm{l}}$ mice compared with that in $A p c^{\mathrm{fl} / \mathrm{fl}}$ control mice $(2099 \pm 286 \mathrm{WT}, 2522 \pm 250 \mathrm{KO}, p<0.05, n=4)$. These data indicate that two-allele $A p c$ disruption in neonatal oligodendroglial lineage cells results in CNS hypomyelination.

\section{APC controls oligodendrocyte differentiation}

We used immunohistochemistry to test the hypothesis that the hypomyelination elicited by biallelic conditional deletion of oligodendroglial lineage $A p c$ resulted from impaired oligodendroglial differentiation. Sox10 is a transcription factor ubiquitously expressed throughout oligodendrocyte development (Stolt et al., 2002; Rivers et al., 2008), and we found that the densities of Sox $10^{+}$oligodendroglial lineage cells were significantly decreased in both spinal cord WM and GM in OCE/Apc $c^{\mathrm{fl} / f \mathrm{l}} \mathrm{Apc} \mathrm{KO}$ mice (Fig. 2G). We confirmed this result by showing that Sox10 mRNA was also decreased by approximately twofold, compared with controls, in OCE/Apc $c^{\mathrm{fl} / \mathrm{fl}}$ mice (Fig. $2 H$ ). Using CC1 as an oligodendrocyte marker (Bhat et al., 1996), we demonstrated that the number of $\mathrm{CC}^{+}$oligodendrocytes per spinal cord section (Fig. $2 \mathrm{I1}-\mathrm{I3}$ ) and the density of Sox $10^{+} / \mathrm{CC}^{+}$oligodendrocytes (Fig. $2 K$ ) in OCE $/ A p c^{\mathrm{fl} / \mathrm{fl}}$ mice were significantly lower than those in $A p c^{\mathrm{fl} / \mathrm{fl}}$ mice. Quantification of cells expressing another oligodendrocyte marker, GST- $\pi$, also showed significantly decreased oligodendrocyte numbers in the spinal cord (Fig. 2J). Because Olig2-Cre-ER ${ }^{\mathrm{T} 2}$ is a knock-in transgene, replacing one of two endogenous Olig2 alleles (Takebayashi et al., 2002), we evaluated the effect of the transgene knock-in itself on oligodendrocyte differentiation, and found that the number of oligodendrocytes was not affected in OCE/Ap $c^{\mathrm{fl} / \mathrm{fl}}$ mice that had not received tamoxifen (i.e., no $A p c$ deletion) compared with $A p c^{\mathrm{fl} / \mathrm{fl}}$ controls $\left(1261 \pm 103\right.$ in $A p c^{\mathrm{fl} / \mathrm{fl}}, 1242 \pm 93$ in OCE $/ A p c^{\mathrm{fl} / \mathrm{fl}}, n=$ $6, p=0.74)$.

We used in situ hybridization to visualize and quantify the frequency of proteolipid protein $(P l p) \mathrm{mRNA}^{+}$oligodendrocytes and found that, upon $A p c$ disruption, $P l p$ mRNA $^{+}$cells were significantly decreased in OCE/Apc $c^{\mathrm{fl} / \mathrm{fl}} \mathrm{KO}$ mice (Fig. $2 L$ ). QRTPCR also demonstrated that levels of mRNAs encoded by the myelin genes $P l p$, Cnp , and $M b p$ were significantly lower in OCE/ $A p c^{\mathrm{fl} / \mathrm{fl}} \mathrm{KO}$ mice than in $A p c^{\mathrm{fl} / \mathrm{fl}}$ controls (Fig. $2 M$ ). In contrast, mRNA levels of $M b p, P l p$, and Cnp were similar in OCE/Apc $c^{\mathrm{fl} / \mathrm{fl}}$ and $A p c^{\mathrm{fl} / \mathrm{fl}}$ mice that had not been given tamoxifen (i.e., no $A p c$ deletion) (Fig. $2 N$ ), again indicating that the OCE knock-in transgene does not affect oligodendrocyte development. In summary, our data indicate that oligodendrocyte differentiation is inhibited in Apc two-allele-deficient mice.

\section{Normal oligodendrocyte differentiation in Apc one-allele KO mice}

We analyzed $A p c$ one-allele $\mathrm{KO}$ mice (OCE/Apc $c^{\mathrm{fl} /+}$ treated with tamoxifen at P6 and P7) to determine whether Apc haploinsufficiency impedes oligodendrocyte development. In sharp contrast to $A p c$ two-allele $\mathrm{KO}$ mice (OCE/Apc $c^{\mathrm{fl} / \mathrm{fl}}$ treated with tamoxifen), the number of $\mathrm{CCl}^{+}$oligodendrocytes and Sox10 mRNA levels in one-allele $A p c \mathrm{KO}$ mice were not significantly different from those in $A p c^{\mathrm{fl} / \mathrm{fl}}$ controls (Fig. $2 \mathrm{H}, \mathrm{I3}$ ) at P14. Also, the number of $P l p \mathrm{mRNA}^{+}$cells in one-allele $A p c \mathrm{KO}$ did not differ from $A p c^{\mathrm{fl} / \mathrm{fl}}$ controls (Fig. $2 L$ ), but was significantly higher than that in twoallele $A p c \mathrm{KO}$ mice (Fig. $2 L$ ). Thus, oligodendrocyte differentiation is not perturbed in $A p c$ one-allele $\mathrm{KO}$ mice.

\section{APC disruption decreases OPC numbers by diminishing OPC proliferation}

The frequency of Sox $10^{+} / \mathrm{NG} 2^{+} \mathrm{OPCs}$ at P14 was significantly lower in $\mathrm{OCE} / A p c^{\mathrm{fl} / \mathrm{fl}} A p c \mathrm{KO}$ mice in both spinal cord WM and GM (Fig. $3 C$ ). At this point in postnatal development, $>90 \%$ of phosphorylated histone $3\left(\mathrm{PH}^{+}\right)$or $\mathrm{Ki}^{+} 7^{+}$mitotic cells in CNS are Sox $10^{+} / \mathrm{NG}^{+}{ }^{+} \mathrm{OPCs}$ (Fig. $3 A 1, A 2 ; \geq 30 \mathrm{PH} 3{ }^{+} \mathrm{OPCs}$ from 3 mice). In OCE $/ A p c^{\mathrm{fl} / \mathrm{fl}} A p c \mathrm{KO}$ mice, numbers of $\mathrm{Ki}^{+} 7^{+} / \mathrm{PH} 3^{+}$ cycling cells per section were significantly below those in $A p c^{\mathrm{fl} / \mathrm{fl}}$ controls (Fig. 3A5). Furthermore, the number of EdU ${ }^{+}$cells $(2 \mathrm{~h}$ labeling) (Fig. 3B1,B2) was also significantly decreased in OCE/ $A p c^{\mathrm{fl} / \mathrm{fl}} A p c \mathrm{KO}$ mice at P14 (74 $\pm 23 \mathrm{WT}, 33 \pm 10 \mathrm{KO}, n=3, p<$ $0.05)$. Cyclin D1 is required for the progression of cell cycle (Baldin et al., 1993; Stacey, 2003), and both cyclin D1 mRNA (Fig. 3E, right) and protein (Fig. $3 D, 3 E$, left) expression levels were approximately twofold lower in OCE/Apc ${ }^{\mathrm{f} / \mathrm{fl}} A p c \mathrm{KO}$ mice than in WT controls. These results indicate that biallelic disruption of Apc inhibits OPC division. By observing no significant difference in activated caspase- $3^{+}$cells, we determined that heightened OPC apoptosis did not contribute to the diminution in numbers of OPCs caused by biallelic APC disruption (WT, $1.8 \pm 0.9$ per section; KO, $1.4 \pm 0.8$ per section; $p=0.56, n=4)$.

\section{Inhibition of oligodendrocyte differentiation persists in adult Apc KO mice}

We conditionally ablated Apc at P6/P7 and analyzed oligodendrocyte differentiation at $\mathrm{P} 40$, yielding mildly tremorous mice. Sox 10 and CC1 double immunohistochemistry (Fig. 4A) demonstrated that the densities of Sox $10^{+}$panoligodendroglial lineage cells and $\mathrm{CC}^{+}{ }^{+}$oligodendrocytes (Fig. $4 A$ ) were significantly reduced in adult $\mathrm{OCE} / A p c^{\mathrm{fl} / \mathrm{fl}} A p c \mathrm{KO}$ mice, compared with $A p c^{\mathrm{fl} / \mathrm{fl}}$ controls (Fig. 4B). Furthermore, mRNA levels of the myelin genes $P l p$ and $C n p$ were significantly decreased in adult OCE/ $A p c^{\mathrm{fl} / \mathrm{fl}} A p c \mathrm{KO}$ mice (Fig. 4C).

Next, we quantified the ratio of OPCs to oligodendrocytes in $A p c \mathrm{KO}$ and control mice. In adult $A p c^{\mathrm{fl} / \mathrm{fl}} \mathrm{WT}$ mice, the ratio of $\mathrm{NG}_{2}{ }^{+} \mathrm{OPC}$ number to $\mathrm{CC} 1{ }^{+}$oligodendrocyte number among Sox $10^{+}$oligodendroglial lineage (OL) cells (Apc-intact) was $\sim 1$ : 11.8 (7.9\% OPCs, 92.9\% OLs) (Fig. 4D, left bar). However the ratio of $\mathrm{EYFP}^{+} \mathrm{NG}^{+}{ }^{+} \mathrm{OPCs}$ to $\mathrm{EYFP}^{+} \mathrm{CC}^{+}{ }^{+}$oligodendrocytes among $\mathrm{EYFP}^{+}$Sox $10^{+}$oligodendroglial lineage cells (Apcdeficient) increased to 1:1.7 (37.2\% $\mathrm{EYFP}^{+} \mathrm{OPCs}, 62.6 \% \mathrm{EYFP}^{+}$ OLs) (Fig. $4 D$, right bar) in adult OCE/Apc $c^{\mathrm{fl} / \mathrm{fl}}$ Rosa-EYFP mice. This marked shift in ratio of OPCs to OLs among EYFP ${ }^{+}, A p c-$ deficient oligodendroglial lineage cells (see Fig. 7D) again suggests that differentiation of OPCs to oligodendroglia is inhibited in adult biallelic Apc KO mice and that the decreased oligodendrocyte density and number (Fig. 2) are not only due to the 

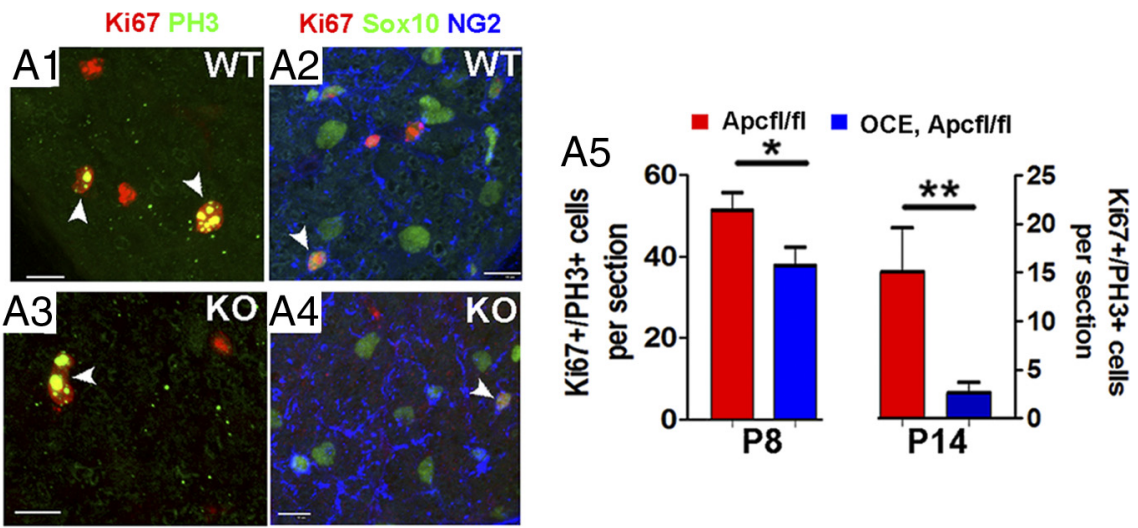

Axin2, Naked1, and Notum (Fancy et al., 2009, 2011). Therefore, immunohistological demonstration of nuclear accumulation of $\beta$-catenin in conjunction with assays for mRNA levels of Wnt target genes provide reliable hallmarks for activation of Wnt signaling. We found that $\beta$-catenin accumulated in the nuclei of $\mathrm{EYFP}^{+}$Apc-deficient oligodendroglial lineage cells (Fig. $5 A-C$ ) in P14 OCE/ $A p c^{\mathrm{fl} / \mathrm{fl}}$ Rosa-EYFP mice. Approximately $85 \%$ of nuclear $\beta$-catenin ${ }^{+}$cells were $\mathrm{EYFP}^{+} / \mathrm{PDGFRa}^{+}$OPCs (Fig. $5 H$ ), while the remainder were $\mathrm{EYFP}^{+} / \mathrm{CC} 1^{+}$differentiated oligodendrocytes (data not shown). Consistently, mRNA levels of Wnt target gene Axin2 and Naked1 were also significantly upregulated in $A p c$ twoallele $\mathrm{KO}$ mice (Fig. $5 G$ ). In adult mice, in contrast, although we observed $\beta$-catenin nuclear accumulation in the $\mathrm{EYFP}^{+}$cells (Fig. 5I), the mRNA levels of Axin2 and Naked1 were similar between P40 OCE/ $A p c^{\mathrm{fl} / \mathrm{fl}} /$ Rosa-EYFP mice and $A p c^{\mathrm{fl} / \mathrm{fl} /}$ Rosa-EYFP controls (Fig. 5J, red bars), thus arguing that $A p c$ ablation does not affect Wnt/ $\beta$-catenin downstream signaling in these adult mice. Together, our data reveal that early postnatal $A p c$ deletion leads to only a transient increase of Wnt/ $\beta$-catenin signaling in oligodendroglial lineage cells.

Unexpectedly, we found that the tran-

Figure 3. Apc deletion reduces $\mathrm{OPC}$ proliferation. Tamoxifen was injected in pups at $\mathrm{P} 6$ and $\mathrm{P} 7$ and $\mathrm{CNS}$ tissues were analyzed as indicated. A1-A5, Confocal images of PH3/Ki67 and PH3/SOX10/NG2 immunostaining and quantifications of cells positive for these markers in $A p c^{\mathrm{fl} / \mathrm{fl}} \mathrm{WT}$ and $\mathrm{OCE} / A p c^{\mathrm{fl} / \mathrm{fl}} \mathrm{KO}(n=3 \mathrm{WT}, 3 \mathrm{KO}$ at P8; $n=10 \mathrm{WT}, 7 \mathrm{KO}$ at P14). B1, B2, Representative confocal images of EdU ( $2 \mathrm{~h}$ labeling). C, The number of Sox $10^{+} / \mathrm{NG2}{ }^{+} \mathrm{OPCs}$ in the spinal WM and GM of P14 Apc $c^{\mathrm{f} / f f} \mathrm{WT}(n=10)$ and OCE/Apc ${ }^{f / / f l} \mathrm{KO}$ mice $(n=7)$. D, Western blot of cyclin D1 in P14 spinal cord. $\boldsymbol{E}$, Quantification of cyclin D1 protein (left) and mRNA (right) levels in P14 Apc $c^{\mathrm{fl} / f 1} \mathrm{WT}(n=4)$ and OCE/Apc ${ }^{\mathrm{fl} / \mathrm{fl}} \mathrm{KO}(n=4)$ mice. Scale bars: $\mathbf{A 1}-\mathbf{A 4}, 10 \mu \mathrm{m} ; \boldsymbol{B 1}, \mathbf{B 2}, 50 \mu \mathrm{m}$.

sient upregulation of Wnt $/ \beta$-catenin signaling occurred in two-allele but not one-allele Apc KO oligodendroglial lineage cells. As shown in Figure $5 D, E$, there were no $\mathrm{EYFP}^{+}$cells with nuclear $\beta$-catenin in one-allele $\mathrm{KO}$ spinal cord, similar to that in $A p c^{\mathrm{fl} / \mathrm{fl}} /$ Rosa-EYFP control mice (Fig.

reduced OPC number (Fig. 3) but also due to the compromised differentiation.

As mentioned above, virtually all Cnp-Cre, $A p c^{\mathrm{fl} / \mathrm{fl}}$ mice died before weaning. Only one Cnp-Cre, $A p c^{\mathrm{fl} / \mathrm{fl}}$ mouse survived into adulthood during extensive attempts at breeding these bitransgenic mice. As shown in Figure $4 E$, this mouse was much smaller than Cnp-Cre, $A p c^{\mathrm{fl} /+}$ littermates, and displayed ataxia and hindlimb paralysis. Double immunohistochemistry with MBP (for myelin) and SMI312 (for axons) showed that most SMI312 ${ }^{+}$ axons in the spinal dorsal horn of this adult Cnp-Cre/Apc $c^{\mathrm{fl} / \mathrm{fl}}$ mouse were still unmyelinated (green when merged) (Fig. $4 F$, arrowhead), whereas almost all the SMI $312^{+}$axons were myelinated (yellow when merged) in a Cnp-Cre/Apc $c^{\mathrm{fl} /+}$ littermate (Fig. $4 G$, arrowhead). Together, these data indicate that oligodendroglial differentiation and myelination are inhibited in adult $A p c$ KO mice, and that one-allele $A p c$ ablation does not affect oligodendrocyte development.

\section{$\mathrm{Wnt} / \boldsymbol{\beta}$-catenin signaling is transiently upregulated in $A p c$ two-allele KO mice}

Upon activation of canonical Wnt signaling, $\beta$-catenin is translocated into the nucleus, where it binds to the Tcf/Lef transcription factor, leading to transcription of the Wnt target genes
$5 F)$. In accord with the absence of nuclear $\beta$-catenin, the mRNA levels of Axin 2 and Naked 1 in one-allele KO mice (OCE/Apc ${ }^{\mathrm{fl} /+}$ ) were not significantly different from those in WT controls (Fig. $5 G$, green and red bars), suggesting $A p c$ one-allele ablation is not sufficient to dysregulate Wnt/ $\beta$-catenin signaling in oligodendroglial lineage cells. To support and confirm this conclusion, we evaluated Wnt/ $\beta$-signaling in heterozygous $A p c^{\mathrm{min} /+}$ mice (Moser et al., 1993), in which one-allele nonsense mutation in codon 850 of the $A p c$ gene leads to a truncated APC polypeptide that lacks the $\beta$-catenin-binding domain. Consistently, mRNA levels of the Wnt/ $\beta$-catenin signaling target genes Axin2, Naked1, and Notum in the spinal cord of $A p c^{\mathrm{min} /+}$ mice were similar to those in $A p c^{+/+}$WT littermates at P7 (Fig. 6A) and in the adult (data not shown). Using Wnt-signaling reporter BAT-lacZ mice (Fig. 6B) (Maretto et al., 2003), we found that the number of $\beta$-gal ${ }^{+}$(lacZ gene product) cells in the ventral spinal cord of $A p c^{\mathrm{min} /+} /$ BAT-lac $Z$ double-transgenic mice ( $25 \pm 5$ per section, $n=4)$ was not significantly different from that in $A p c^{+/+} / \mathrm{BAT}$ lacZ littermates ( $23 \pm 6$ per section, $n=3$ ) at P7 (Fig. $6 C$ ) and in the adult (data not shown). Collectively, these data indicate that (1) Apc one-allele $\mathrm{KO}$ is not sufficient to dysregulate $\mathrm{Wnt} / \beta$ catenin signaling, and (2) Apc two-allele ablation leads to tran- 
A

产
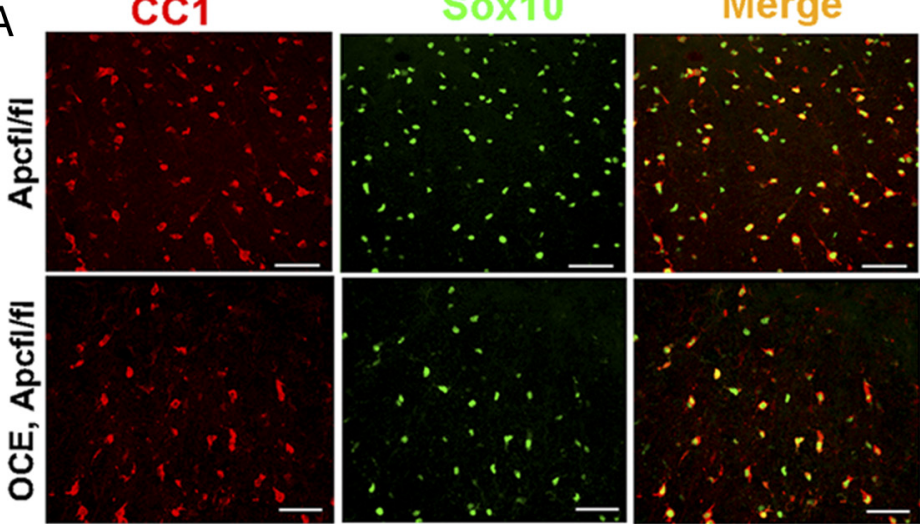

C

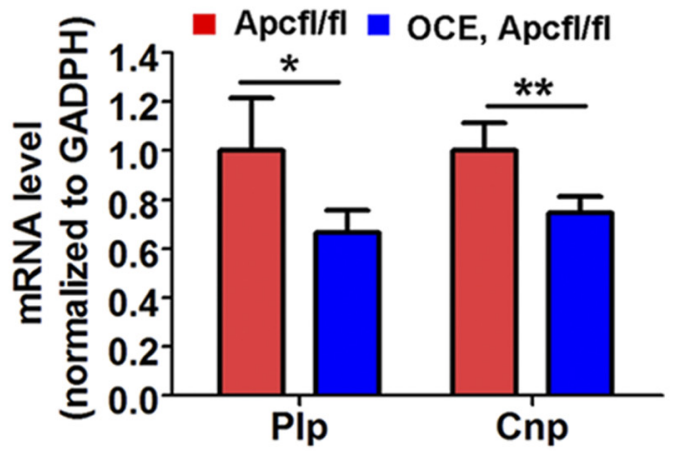

$E$

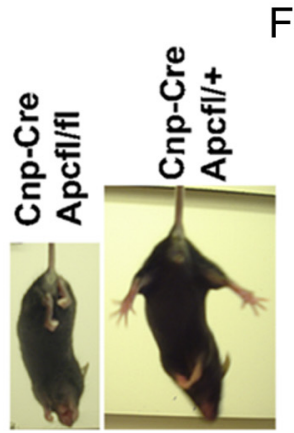

F

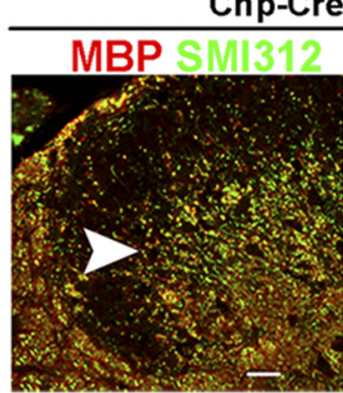

Cnp-Cre, Apcfl/+ SMII12

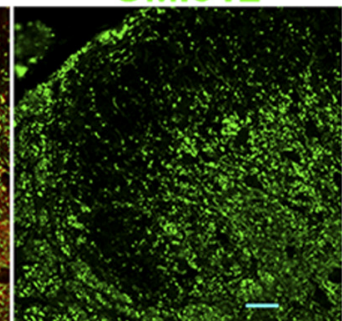

B

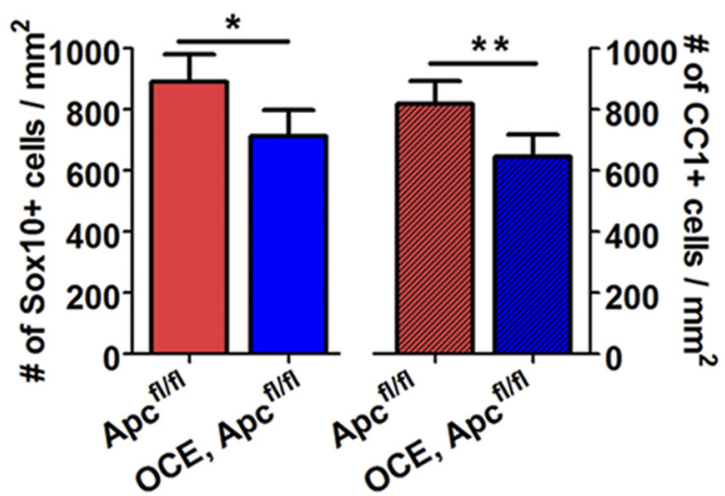

D

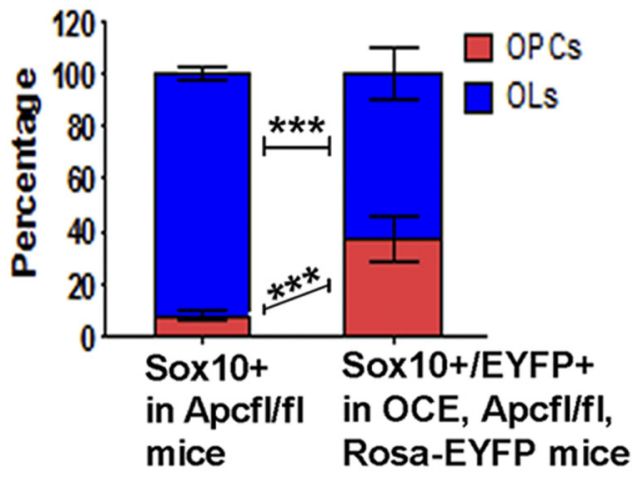

G

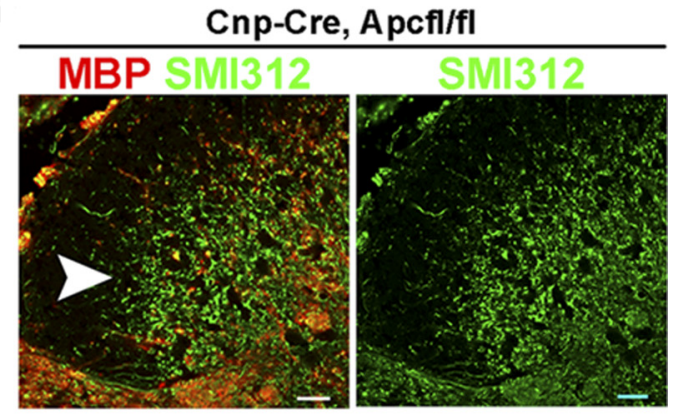

Figure 4. Inhibition of oligodendrocyte differentiation and myelination persists in the adult CNS. Tamoxifen was injected in pups at P6 and P7 and CNS tissues were analyzed at P40. A, Representative confocal images showing Sox10 and CC1 double immunostaining in P40 spinal cord. B, Quantifications of Sox $10^{+}$oligodendroglial lineage cells (left) and CC1 + oligodendrocytes (right) in P40 Apc ${ }^{\mathrm{f} / \mathrm{fl}} \mathrm{WT}(n=6)$ and OCE/Apc ${ }^{\mathrm{fl} / f \mathrm{l}} \mathrm{KO}(n=4)$ spinal cord. C, Plp and Cnp mRNA expression levels in P40 Apc $c^{\mathrm{fl} / \mathrm{fl}} \mathrm{WT}(n=6)$ and OCE/Apc $c^{\mathrm{fl} / f \mathrm{~K}} \mathrm{KO}(n=4)$ spinal cord by qRT-PCR. D, Proportions of Sox $10^{+} / \mathrm{NG}^{+} \mathrm{OPCs}$ and Sox $10^{+} / \mathrm{CC}^{+}{ }^{+} \mathrm{OLs}$ among total Sox $10^{+}$oligodendroglial lineage cells in P40 Apc ${ }^{\mathrm{fl} / \mathrm{ll}}$ WT spinal cord $(n=6)$ (left bar) and proportions of EYFP ${ }^{+} / \mathrm{Sox} 10^{+} /$

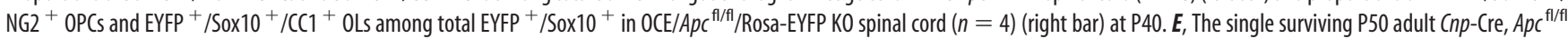
mouse displayed hind-limb paralysis (left), whereas a $\mathrm{Cnp}$-Cre/Apc ${ }^{\mathrm{fl} /+}$ littermate did not (right). $\boldsymbol{F}, \mathbf{G}, \mathrm{MBP}$ and SMI312 double IHC revealed severe hypomyelination (SMI312 ${ }^{+} / \mathrm{MBP}^{-}$naked axon fibers, green when overlaid) in the spinal cord dorsal horn (arrowheads) of the $C n p$ - $C r e / A p c^{\mathrm{fl} / f l}$ mouse $(G)$, compared with normal myelination in a $\left(n p-C r e / A p c^{\mathrm{fl} /+}\right.$ littermate $\left(\boldsymbol{F}, \mathrm{SMI}_{312}{ }^{+} / \mathrm{MBP}^{+}\right.$ axons, yellow when overlaid). Scale bars: $50 \mu \mathrm{m}$, applied to all.

sient upregulation of this signaling in the early postnatal CNS, but not in the adult.

Oligodendrocyte differentiation is not perturbed in the $A p c^{\mathrm{min} /+}$ mice

Our data demonstrate that neither $A p c$ one-allele nonsense truncated mutation (Fig. $6 A-C$ ) nor one-allele conditional $\mathrm{KO}$ (Fig. $5 A-G)$ dysregulates $\mathrm{Wnt} / \beta$-catenin signaling in oligodendroglial lineage cells. These findings led us to assess whether oligodendrocyte development is perturbed in $A p c^{\mathrm{min} /+}$ mice. To this end, we evaluated oligodendroglial differentiation in $A p c^{\mathrm{min} /+}$ and $A p c^{+/+}$littermate control mice at P7, a time point when oligodendroglial Wnt $/ \beta$-catenin signaling is most active (Fancy et al., 2009, 2011).
Double immunohistochemistry with the panoligodendroglial lineage marker Sox10 and the OPC marker PDGFR $\alpha$ revealed comparable immunostaining patterns in the $\mathrm{P} 7$ spinal cord of $A p c^{\mathrm{min} /+}$ (Fig. 6E) and $A p c^{+/+}$mice (Fig. 6D). Quantification in different areas of spinal cord-ventral WM, lateral WM, corticospinal tract, and GM (Fig. 6F)-showed that the densities of $\mathrm{Sox}_{10}{ }^{+}$oligodendroglial lineage cells (Fig. 6G), Sox $10^{+}$PDGFR $\alpha^{+}$OPCs (Fig. $6 H$ ), and Sox $10^{+}$PDGFR $\alpha{ }^{-}$oligodendrocytes (Fig. 6I) were comparable between $A p c^{\mathrm{min} /+}$ and $A p c^{+/+}$mice (Fig. $6 F$ ), suggesting that the oligodendroglial population and differentiation are not affected in $A p c^{\mathrm{min} /+}$ mice. This was further supported by qRT-PCR showing similar expression of the myelin genes Cnp, Mbp, and $P l p$ in $A p c^{\min /+}$ and $A p c^{+/+}$mice (Fig. $6 J$ ). Moreover, in contrast to decreased cyclin 


\section{OCE APCfl/fl EYFP(two-allele KO)}
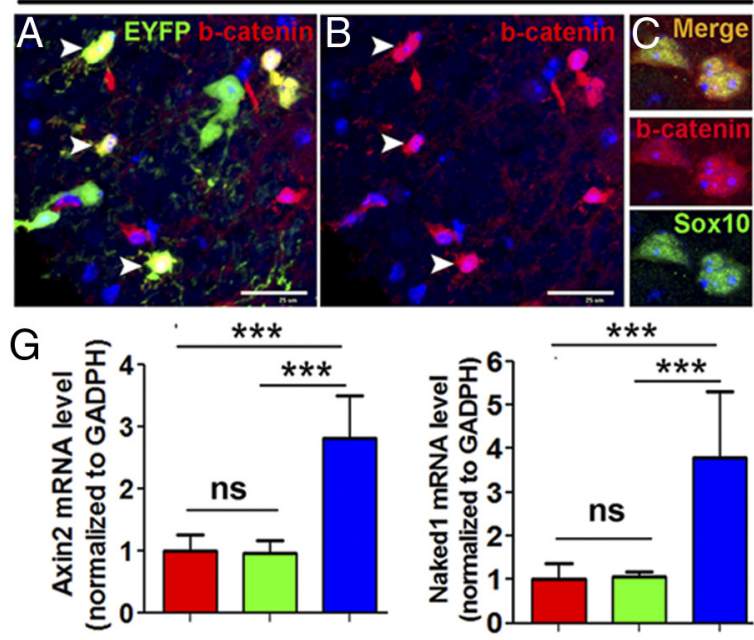

OCE APCfl/+ EYFP (one-allele KO)

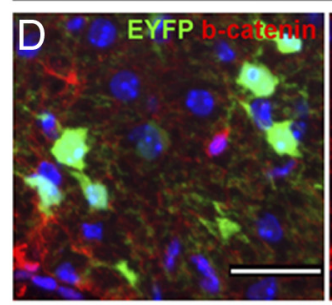

APCfl/fI EYFP(WT)
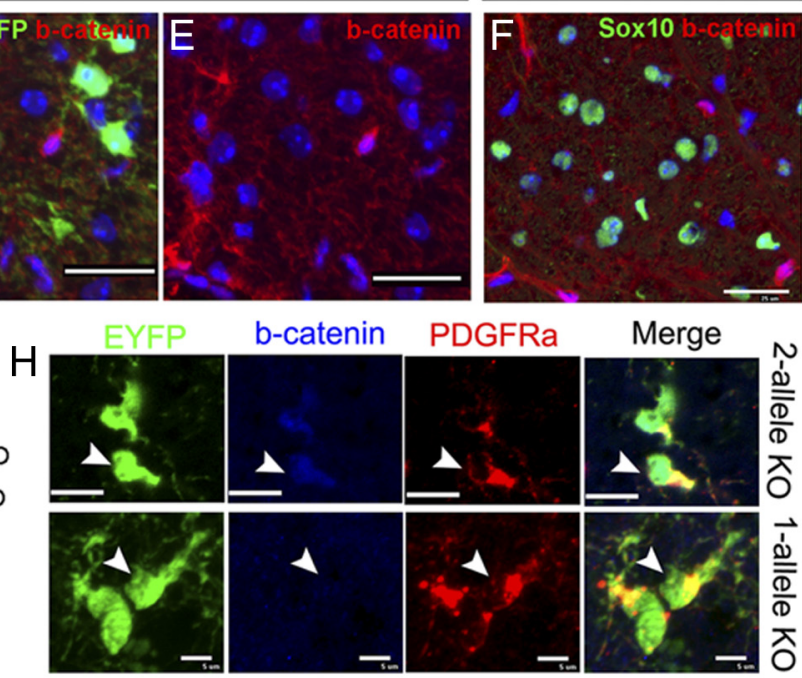
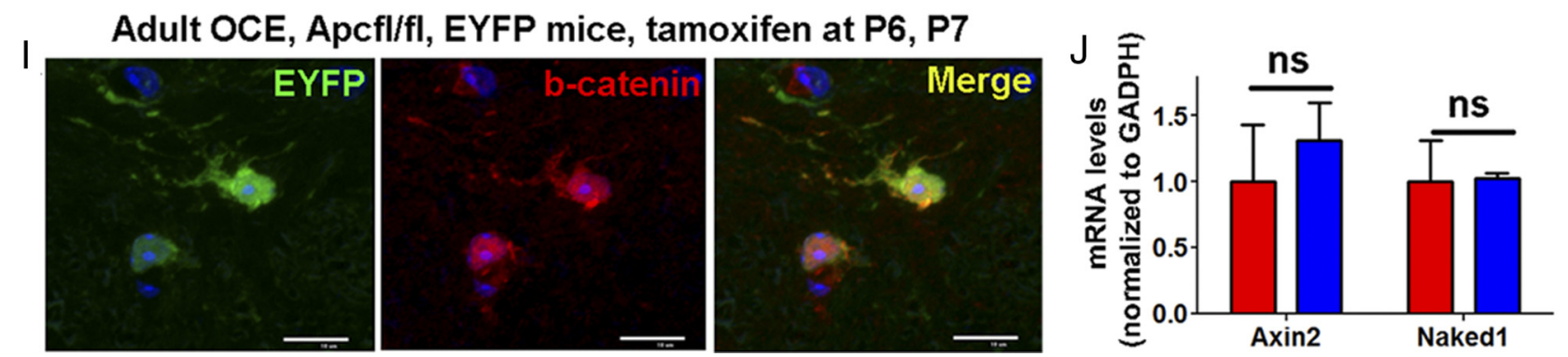

Figure 5. $\quad \beta$-Catenin-dependent Wnt signaling is upregulated in Apc two-allele deleted oligodendroglial lineage cells. Tamoxifen was injected in pups at P6 and P7 and CNS tissues were analyzed as indicated. $\boldsymbol{A}-\boldsymbol{F}, \boldsymbol{\beta}$-Catenin accumulated in the nuclei of EYFP ${ }^{+} / \mathrm{SOX} 10^{+}$cells in Apc two-allele $(\boldsymbol{A}-\boldsymbol{C})$ but not in Apc one-allele K0 (D, E) or WT spinal cord at P14 (F). $\boldsymbol{G}$, MRNA levels of Wnt target genes Axin2 and Naked 1 in Apc two-allele $(n=7)$, one-allele $(n=4)$, and WT $(n=10)$ spinal cord at P14. $\boldsymbol{H}$, Triple IHC showing nuclear accumulation of $\beta$-catenin in EYFP ${ }^{+} /$PDGFR $\alpha{ }^{+}$OPCs from two-allele (top) but not one-allele (bottom) Apc-KO mice. I, Double IHC of EYFP and $\beta$-catenin in P40 OCE/Apc fl/fl/Rosa-EYFP, tw0-allele Apc KO spinal cord. J, Axin2 and Naked1 expression levels in $\mathrm{P} 40 A p c^{\mathrm{fl} / \mathrm{fl}}$ (red bars, $n=6$ ) and OCE, $A p c^{\mathrm{fl} / \mathrm{fl}}$ (blue bars, $n=4$ ) spinal cord. Scale bars: $\boldsymbol{A}-\boldsymbol{F}, 50 \mu \mathrm{m} ; \boldsymbol{H}, 5 \mu \mathrm{m} ; \boldsymbol{I}, 10 \mu \mathrm{m}$.

D1 levels (Fig. $3 D, E$ ) in Apc two-allele conditional KO, comparable cyclin D1 mRNA levels between $A p c^{\mathrm{min} /+}$ and $A p c^{+/+}$controls (Fig. $6 J$ ) indicated that oligodendroglial proliferation was not affected in $A p c^{\mathrm{min} /+}$ mice. We also did not detect differences in oligodendroglial differentiation between P30 $A p c^{\mathrm{min} /+}$ and $A p c^{+/+}$control littermates (data not shown). These data suggest that oligodendroglial development and differentiation are normal in $A p c^{\mathrm{min} /+}$ mice.

\section{$\boldsymbol{\beta}$-Catenin is dispensable for postnatal}

oligodendrocyte differentiation

Dominant active $\beta$-catenin (Cre-LoxP-mediated deletion of exon 3 of $C t n n b 1$, which results in a mutated $\beta$-catenin escaping degradation) inhibits oligodendrocyte differentiation (Fancy et al., 2009; Feigenson et al., 2009; Ye et al., 2009). Our data suggested that $\beta$-catenin-mediated Wnt-signaling overactivation contributed, at least in part, to the biallelic Apc-disruptionelicited inhibition of oligodendroglial differentiation (Fig. 5) (Fancy et al., 2009; Feigenson et al., 2009; Ye et al., 2009). To determine whether Apc disruption inhibits oligodendroglial differentiation exclusively through a Wnt/ $\beta$-catenin-dependent mechanism, we simultaneously deleted $A p c$ and $C t n n b 1$ (gene for $\beta$-catenin), and unexpectedly found that $\beta$-catenin is dispensable for postnatal oligodendrocyte differentiation.

When intercrossed with a Cre driver, $\beta$-catenin is successfully inactivated in $C t n n b 1^{\text {exon2-6flox/flox }}$ mice $\left(C t n n b 1^{\mathrm{fl} / \mathrm{fl}}\right.$ ) (Brault et al., 2001). Using NG2-Cre (Zhu et al., 2008; Guo et al., 2012), we confirmed that Ctnnb1 mRNA in the spinal cord of NG2-Cre/ $C t_{n} b 1^{\mathrm{fl} / \mathrm{fl}}$ mice was reduced by $\sim 18 \%$ compared with $C t n n b 1^{\mathrm{fl} / \mathrm{fl}}$ controls (Fig. 7A). Based on the previous literature, we postulated that early postnatal ablation of Ctnnb1, when Wnt/ $\beta$-catenin signaling is most active in the oligodendroglial lineage, would elicit precocious OPC differentiation. Some of the NG2-Cre/ Ctnnb1 ${ }^{\mathrm{fl} / \mathrm{fl}}$ mice displayed loss of hair and smaller body-size phenotypes (data not shown). However, expression of the myelin genes Plp and Mbp (Fig. 7A), densities of Sox $10^{+}$panoligodendroglial lineage cells and Sox $10^{+} \mathrm{NG} 2{ }^{+}$OPCs (Fig. 7B), and the proportions of Sox $10^{+} \mathrm{NG}^{+}$OPCs (Fig. 7D1) and Sox $10^{+} \mathrm{NG} 2^{-}$OLs (Fig. 7D2) were similar in NG2-Cre/ $C$ tnnb $^{\mathrm{fl} / \mathrm{fl}}$ mice compared with Ctnnb1 $1^{\mathrm{fl} / \mathrm{fl}}$ controls (Fig. 7C). Thus, disruption of Ctnnb1 does not perturb early postnatal OPC differentiation. We obtained similar results when we evaluated $\mathrm{OPC}$ differentiation at $\mathrm{P} 26$ in NG2-Cre/Ctnnb1 $1^{\mathrm{f} / \mathrm{fl}}$ and $C t n n b 1^{\mathrm{fl} / \mathrm{fl}}$ control mice (Fig. $7 E-G$ ). Thus, $\beta$-catenin is dispensable for postnatal OPC differentiation.

Since the NG2 promoter and NG2-Cre transgene are active not only in OPCs but also in vascular pericytes (Zhu et al., 2008), we next used inducible OCE to specifically ablate Ctnnb1 in oligodendroglial lineage cells. Using the same tamoxifen injection paradigm as in OCE $/ A p c^{\mathrm{fl} / \mathrm{fl}}$ neonates (Fig. 2) (see Materials and Methods), we found that Ctnnb1 mRNA levels were 33\% lower in spinal cord of OCE/Ctnnb1 $1^{\mathrm{fl} / \mathrm{fl}}$ mice than in $C t n n b 1^{\mathrm{fl} / \mathrm{fl}}$ controls at 

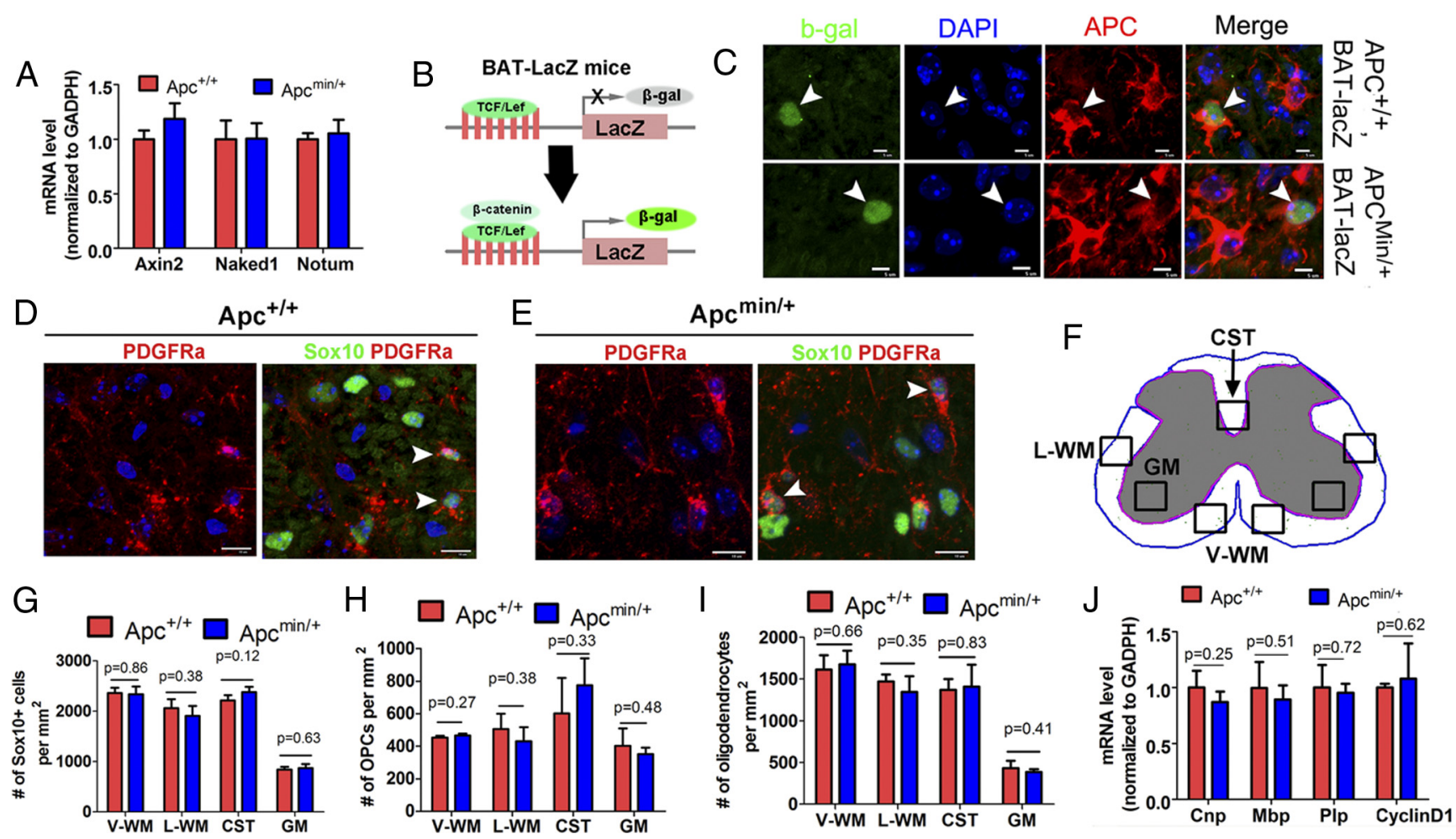

Figure 6. Wnt signaling and oligodendrocyte differentiation are not perturbed in $A p c^{\text {min/+ }}$ mice. $A$, MRNA levels of Wnt target genes $A x i n 2, N a k e d 1$, and Notum in $A p c^{\text {min/ }+}$ ( $\left.n=4\right)$ and $A p c^{+/+}$ WT $(n=4)$ spinal cord at P7.B, Schematic drawing showing the mechanism of $\beta$-gal expression in BAT-lacZ Wnt reporter mice. $C, \beta$-Gal expression in APC ${ }^{+}$cells from BAT-lacZ/ApC ${ }^{+/+}$(top) and BAT-lacZ/Apc ${ }^{\mathrm{min} /+}$ mice (bottom) at P7.D-E, Representative confocal images showing Sox $10^{+}$oligodendroglial lineage cells and Sox10 ${ }^{+} / \mathrm{PDGFR} \alpha^{+}$OPCs in the WM of $A p C^{+/+}$and $A p c^{\text {min/ } /+}$ spinal cord at P7. F, Schematic image depicting the sampling locations for G-I. V-WM, ventral WM; L-WM, lateral WM; CST, corticospinal tract. G-I, Quantifications of the frequency of Sox10 panoligodendroglial lineage cells $(\boldsymbol{G})$, Sox $10^{+} / \mathrm{PDGFR} \alpha^{+} \mathrm{OPCS}(\boldsymbol{H})$, and Sox $10^{+} / \mathrm{CC} 1^{+}$oligodendrocytes $(\boldsymbol{I})$ in the spinal cord at P7 $(n=4$ in each group). $\boldsymbol{J}, \mathrm{MRNA}$ expression level of $C n p, M b p$, PIp, and cyclin D1 by qRT-PCR in P7 Apc ${ }^{+/+}$and $A p c^{\mathrm{min} /+}$ spinal cord ( $n=4$ in each group). Scale bars: $C, 5 \mu \mathrm{m} ; \boldsymbol{D}, \boldsymbol{E}, 10 \mu \mathrm{m}$.

P14 (Fig. 7H, left), but OPC differentiation was not altered (Fig. $7 \mathrm{H}-\mathrm{J})$.

A previous study used Cnp-Cre to successfully ablate Ctnnb1 in mouse embryos (Ye et al., 2009). We postulated that if Ctnnb1 ablation promotes OPC differentiation, as it promotes precocious OPC generation from neural stem cells in embryos (Ye et al., 2009), we would expect to see increased numbers of Plp mRNA ${ }^{+}$oligodendrocytes and elevated levels of myelin gene expression at $\mathrm{P} 1$, the time point at which OPC differentiation is initiated. However, we did not detect a difference in $P l p$ mRNA $^{+}$cells by in situ hybridization in the spinal cord of $\mathrm{P} 1$ Cnp-Cre/Ctnnb $1^{\mathrm{fl} / \mathrm{fl}}$ pups, compared with $C t n n b 1^{\mathrm{fl} / \mathrm{fl}}$ controls (data not shown). QRT-PCR quantification showed that levels of myelin $M b p, P l p$, and Mag mRNAs and levels of oligodendroglial marker Sox 10 mRNA in P1 Cnp-Cre/Ctnnb $1^{\mathrm{fl} / \mathrm{fl}}$ pups to $C \operatorname{tnnb} 1^{\mathrm{fl} / \mathrm{fl}}$ were similar to those in controls. However, Cnp mRNA was decreased by $\sim 50 \%$ (Fig. $7 \mathrm{~K}$ ). This lower Cnp mRNA level was presumably due to the haploinsufficiency of Cnp gene transcription, since Cnp-Cre is a knock-in transgene replacing one of the two endogenous Cnp alleles (Lappe-Siefke et al., 2003).

Collectively, our data demonstrate that oligodendroglial differentiation is not perturbed upon Ctnnb1 disruption, and suggest that $\beta$-catenin is dispensable for postnatal oligodendroglial differentiation under physiological conditions, although its overactivation inhibits oligodendroglial differentiation (Fancy et al., 2009; Feigenson et al., 2009; Ye et al., 2009; Chew et al., 2011).

\section{APC regulates oligodendroglial differentiation through additional $\boldsymbol{\beta}$-catenin-independent mechanisms}

Because $\beta$-catenin ablation does not affect postnatal oligodendroglial development (Fig. 7), we used $A p c$ and Ctnnb1 conditionally double $\mathrm{KO}(\mathrm{dKO})$ mice to dissect the $\beta$-catenin-independent role of $A p c$ in oligodendroglial differentiation. We demonstrated that $\beta$-catenin-mediated Wnt signaling was no longer elevated in $\mathrm{dKO}$ mice (Fig. 8E). Quantification data showed that the density of nuclear $\beta$-catenin ${ }^{+}$cells in $\mathrm{dKO}$ mice was significantly reduced compared with that in $A p c \mathrm{KO}$ mice (Fig. $8 A-C$ ) and was indistinguishable from that in WT mice (Fig. $8 C$ ). In both WT (Fig. $8 D$ ) and dKO spinal cord (Fig. 8D), many nuclear $\beta$-catenin ${ }^{+}$cells viewed at low magnification proved at higher magnification to be closely associated with blood vessels, as evidenced by the association of nuclear $\beta$-catenin and the pericyte marker PDGFR $\beta$ (Fig. $8 D$, arrowheads). Few nuclear $\beta$-catenin ${ }^{+}$cells observed in normal postnatal development belonged to the Sox $10^{+}$oligodendroglial lineage (data not shown). In contrast, $>95 \%$ of nuclear $\beta$-catenin ${ }^{+}$cells in $A p c \mathrm{KO}$ mice were $\mathrm{EYFP}^{+} A p c$-deficient oligodendroglial lineage cells (Fig. 8A). Consistent with the loss of $\beta$-catenin, the elevated Axin2 mRNA level observed in Apc KO mice was abolished in $\mathrm{dKO}$ mice (Fig. $8 F$ ). Together, our results demonstrate that $\mathrm{dKO}$ of $A p c$ and $C t n n b 1$ provides an in vivo model with which to dissect the $\beta$-catenin-independent role of APC in oligodendroglial lineage cells.

If the inhibition of oligodendroglial differentiation mediated by Apc disruption (Fig. 2) is caused solely by dysregulated $\beta$-catenin-mediated Wnt signaling, one would expect that oligodendroglial differentiation in $\mathrm{dKO}$ mice would resemble that in 

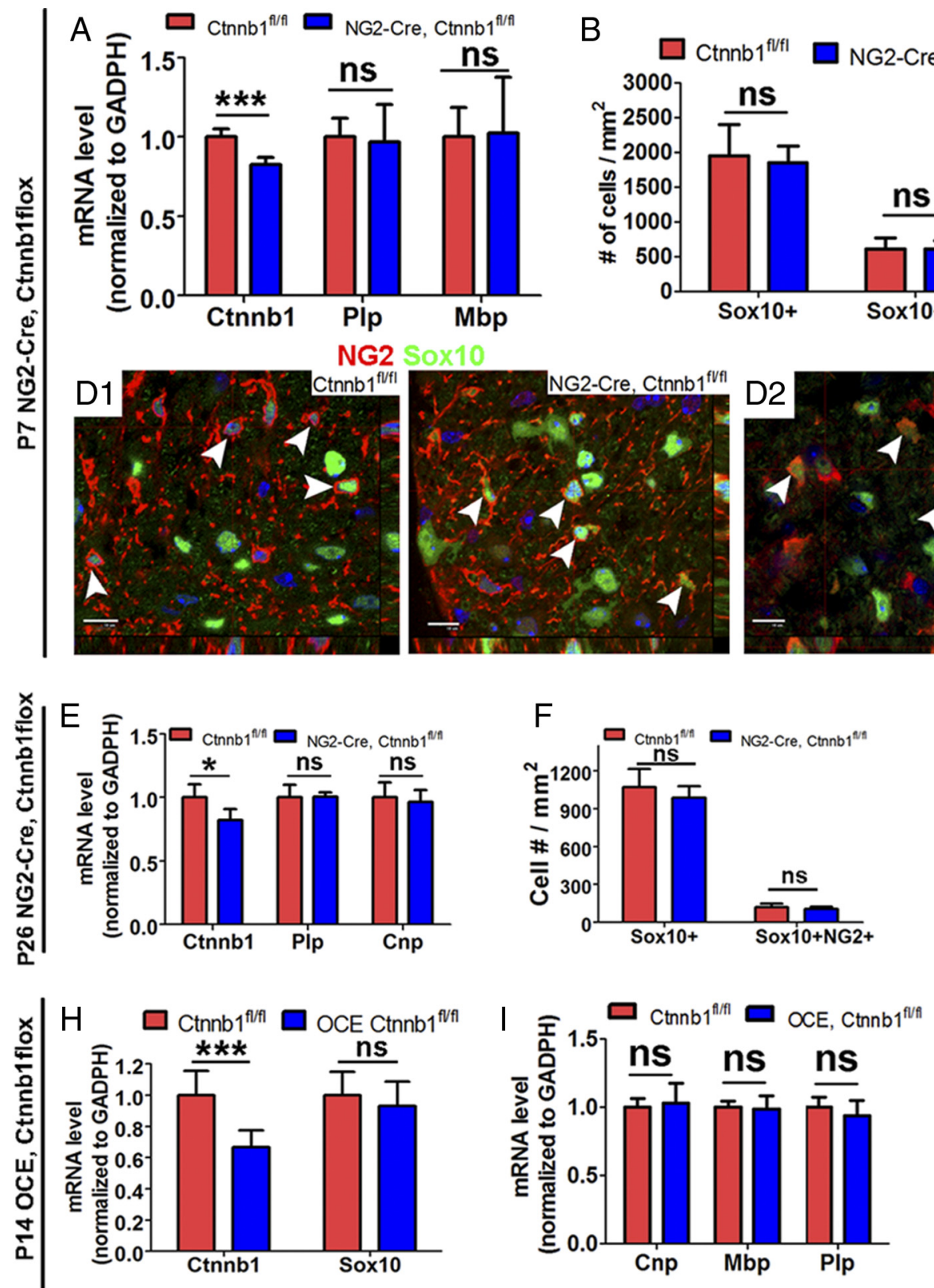

B

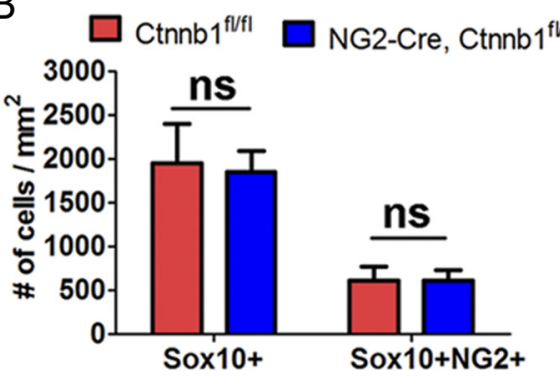

C

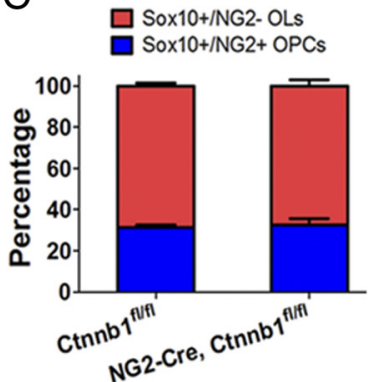

\section{CC1 Sox10}
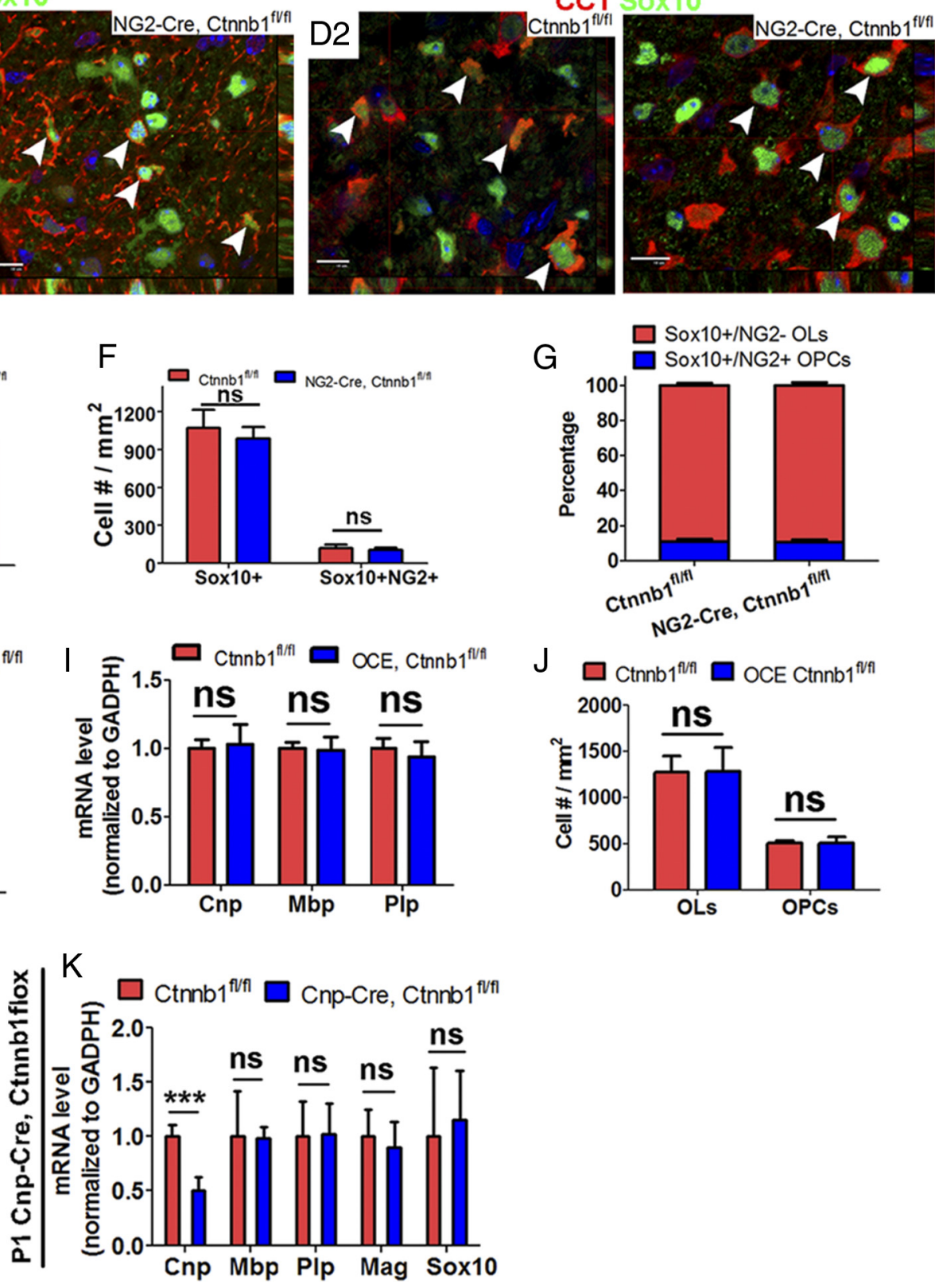

Figure 7. $\beta$-Catenin is dispensable for postnatal oligodendrocyte differentiation. $A, Q R T$-PCR quantification of mRNAs encoded by the Ctnnb1 (gene for $\beta$-catenin) and the myelin genes, Plp and Mbp, in P7

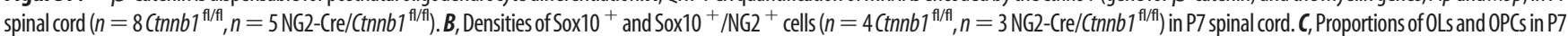

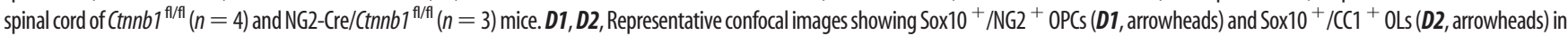

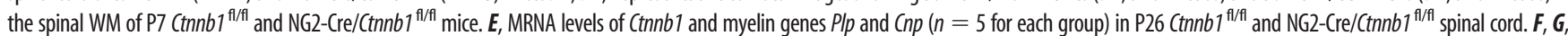
Quantifications of Sox $10^{+}$oligodendroglial lineage cells and Sox $10^{+} / \mathrm{NG2}{ }^{+} \mathrm{OPCS}(\boldsymbol{F})$, and the proportions of OPCs and OLs in the spinal cord at P26 (G) $(n=5$ for each group) $(\boldsymbol{K})$. $\boldsymbol{H}, \boldsymbol{I}, \mathbf{Q u a n t i f i c a t i o n s ~ o f ~} \mathrm{mRNA}$

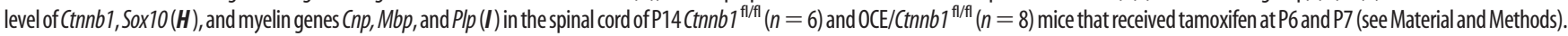

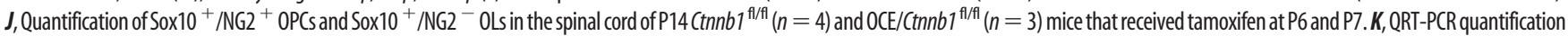
of Cnp, Mbp, Plp, Mag, and Sox10 in the spinal cord of P1 Ctnnb $7^{f / f / f}(n=4)$ and Cnp-Cre/Ctnnb $7^{f / / f}(n=4)$ pups. Scale bars, $10 \mu \mathrm{m}$. 


\section{OCE, Apc ${ }^{\text {fl/fl }}$, Rosa-EYFP (ApcKO) TM P6, P7, analysis P14}
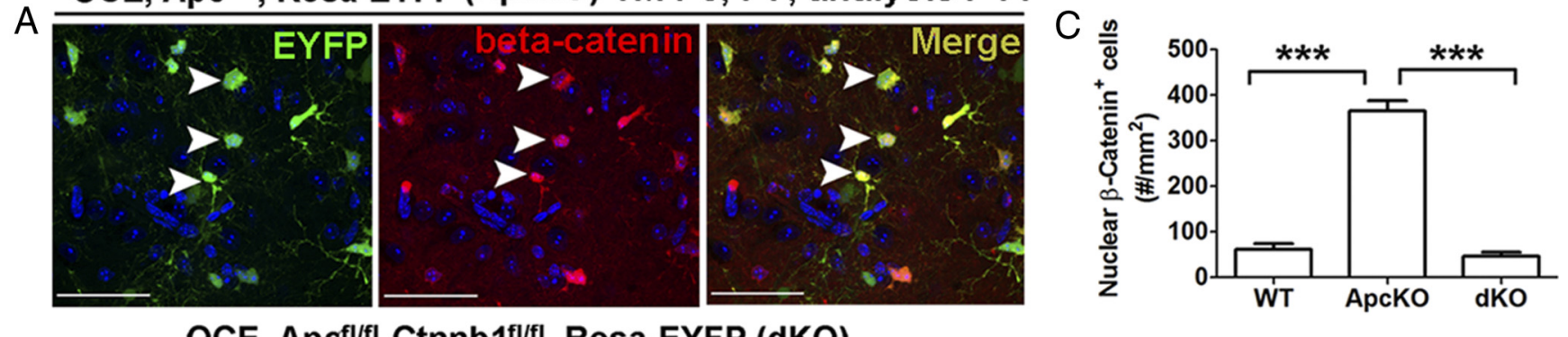

$\mathrm{B}$
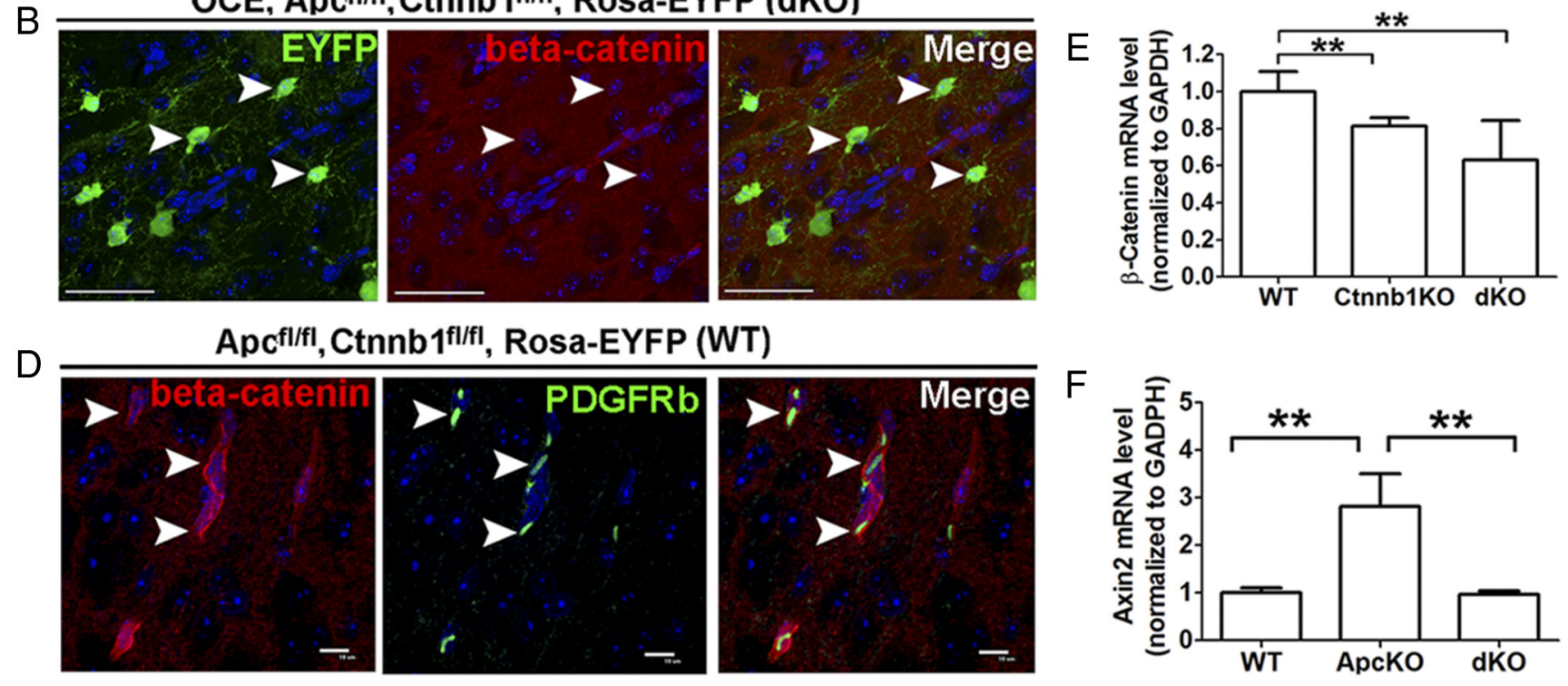

nb1 fl/fl, Rosa-EYFP (WT)
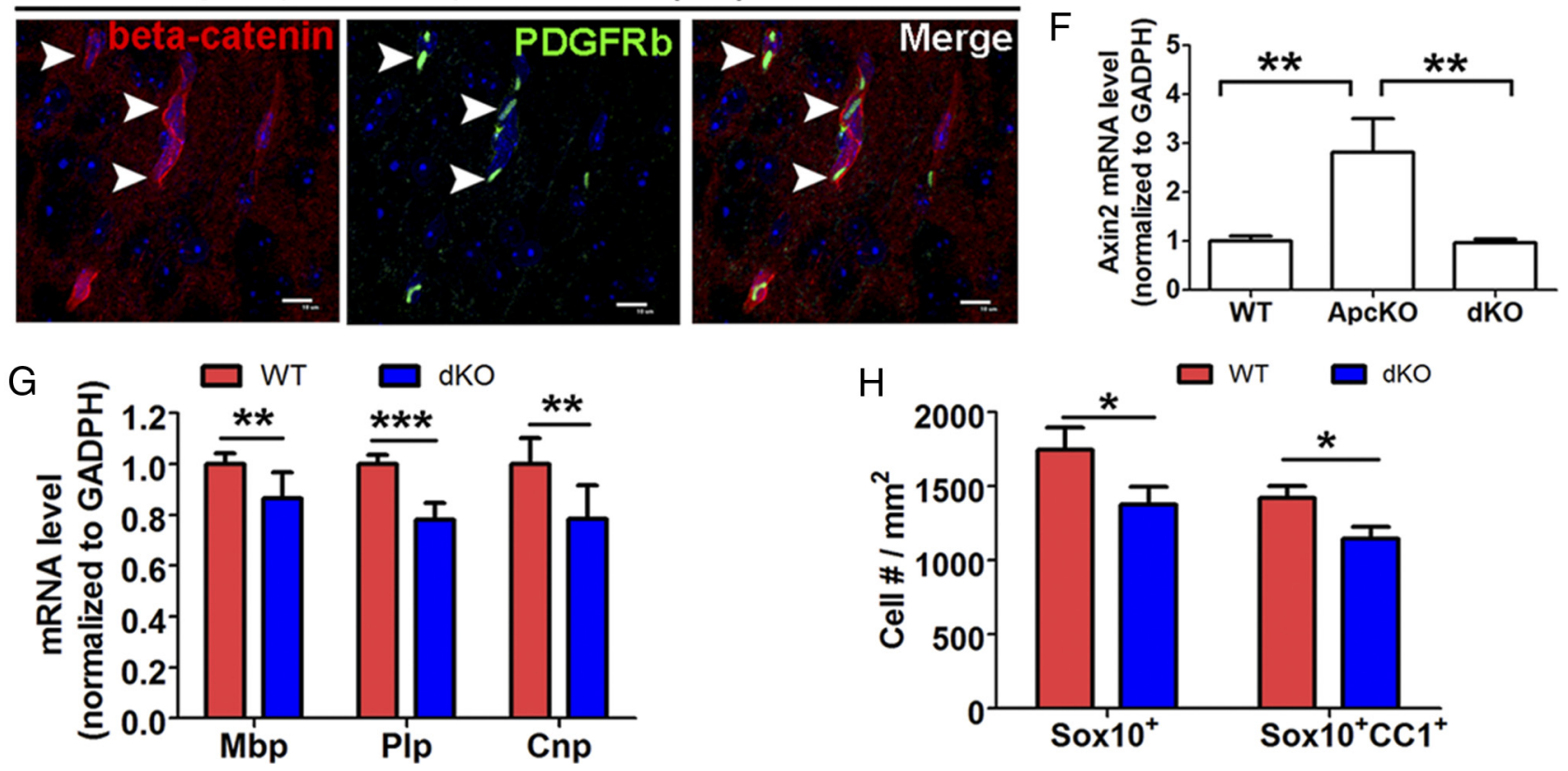

Figure 8. Inhibition of oligodendrocyte differentiation in Apc and Ctnnb1 double-conditional K0 mice. Tamoxifen was injected in pups at P6 and P7 and tissues were analyzed at P14. $\boldsymbol{A}, \boldsymbol{B}, \mathrm{D}$ ouble

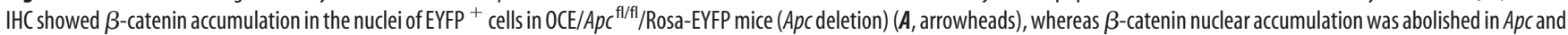
Ctnnt1 dKO mice ( $\boldsymbol{B}$, arrowheads). $\boldsymbol{C}$, Quantification of nuclear $\beta$-catenin ${ }^{+}$cells among each genotype at P14 ( $n=3$ for each group). $\boldsymbol{D}$, Nuclear $\beta$-catenin ${ }^{+}$cells in the WT spinal cord were associated with PDGFR $\beta$-expressing pericytes (arrowheads). $\boldsymbol{E}$, Quantification of (tnnb1 mRNA in each genotype at P14 ( $n=3$ in WT and dK0, $n=4$ in Ctnnb1 K0). $F$, The expression level of Wnt target gene Axin2 was comparable between dKO and WT mice ( $n=3$ in WT and dKO; $n=7$ in Apc KO). G, QRT-PCR quantification showed that expression of myelin genes PIp, Mbp, and Cnp was significantly reduced in spinal cords of P14 dKO mice $\left(n=7\right.$ in WT; $n=5$ in dKO). $\boldsymbol{H}$, Densities of Sox $10^{+}$oligodendroglial lineage cells and Sox $10^{+} C\left(1^{+}\right.$oligodendrocytes in the spinal cord of P14 WT and dK0 mice ( $n=3$ in each group). Scale bars: $A, B, 50 \mu \mathrm{m} ; \boldsymbol{D}, 10 \mu \mathrm{m}$.

WT mice. On the contrary, we found that expression levels of three major myelin genes, $P l p, M b p$, and Cnp (Fig. 8G), were significantly lower in $\mathrm{dKO}$ spinal cord compared with spinal cord of WT controls, in sharp contrast to their normal expression in Ctnnb1 KO mice (Fig. 7I). In addition, Sox10 and CC1 immunostaining showed that the densities of both Sox $10^{+}$panoligodendroglial lineage cells and Sox $10^{+} \mathrm{CC}^{+}$oligodendrocytes (Fig. $8 \mathrm{H}$ ) were significantly decreased in dKO mice, compared with WT mice, suggesting that oligodendroglial differentiation is disturbed in $\mathrm{dKO}$ mice. This is consistent with the finding that $A p c$ disruption causes hypomyelination that persists into adulthood (Fig. 4), when $\beta$-catenin stabilization is not sufficient to activate
Wnt signaling (Fancy 2009). Collectively, our experiments demonstrate a $\beta$-catenin-independent role of APC in regulating oligodendroglial differentiation.

Microarray analysis reveals cytoskeleton dysregulation upon Apc disruption

We used microarray gene expression profiling to search for genes and gene clusters that were dysregulated by Apc deletion. Analyses of raw microarray data obtained from four WT and four Apc KO spinal cords (see Materials and Methods) revealed 336 genes with altered expression of $\geq 1.2$-fold change and $p \leq 0.05$ with FDR correction (gene list available on request). Next, we used 
A

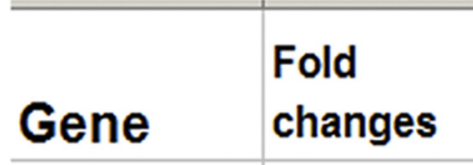

\begin{tabular}{l|l|}
\hline Casr & 4.63 \\
\hline Parvb & 4.06 \\
\hline Rras2 & 3.81 \\
\hline Rnf122 & 3.67 \\
\hline Gpr17 & 3.60 \\
\hline
\end{tabular}

Alox5 $\quad 3.57$

Tns3

3.41

$8030451 \mathrm{~F}$

3.37

1810041L

3.17

Tmem141

3.10

Cnksr3

Tnni1 3.09

\begin{tabular}{l|l|}
\hline Ddc & 2.87 \\
\hline Zfp488 & 2.85
\end{tabular}

Rasgef1b| 2.83

\begin{tabular}{l|r|}
\hline Bcas1 & 2.74 \\
\hline Tnr & 2.70 \\
\hline Nkd1 & 2.64 \\
\hline Slc44a1 & 2.57 \\
\hline Itpr2 & 2.53 \\
\hline Bfsp2 & 2.50 \\
\hline Tcf7l2 & 2.49 \\
\hline Plxnb3 & 2.42 \\
\hline Cxcr4 & 2.41
\end{tabular}

B

\begin{tabular}{|l|r|r|r|} 
& $\begin{array}{r}\text { ApcKo vs WT } \\
\text { by Microarray }\end{array}$ & $\begin{array}{l}\text { ApcKo vs WT } \\
\text { by qRT-PCR }\end{array}$ & $\begin{array}{l}\text { p value } \\
n=10 \mathrm{WT} \\
\text { n=7 KO }\end{array}$ \\
\hline Casr & 4.6 & 21.5 & $1.2 \mathrm{E}-04$ \\
\hline Rnf122 & 3.7 & 6.5 & $1.0 \mathrm{E}-06$ \\
\hline Kif19a & 2.4 & 4.0 & $2.9 \mathrm{E}-03$ \\
\hline Tcf712 & 2.5 & 4.4 & $3.2 \mathrm{E}-07$ \\
\hline Fyn & 1.9 & 4.1 & $1.9 \mathrm{E}-06$ \\
\hline Sox10 & 1.9 & 2.4 & $4.8 \mathrm{E}-04$ \\
\hline CyclinD & 1.5 & 2.1 & $1.4 \mathrm{E}-03$ \\
\hline Dlg1 & 1.3 & 1.6 & $1.2 \mathrm{E}-05$ \\
\hline Nkd1 & 2.7 & 3.3 & $2.7 \mathrm{E}-05$ \\
\hline Cxcr4 & 2.4 & 3.6 & $1.7 \mathrm{E}-06$ \\
\hline Axin2 & 1.7 & 3.2 & $2.3 \mathrm{E}-07$ \\
\hline Cx3cl1 & 1.2 & 1.8 & $3.9 \mathrm{E}-03$ \\
\hline
\end{tabular}
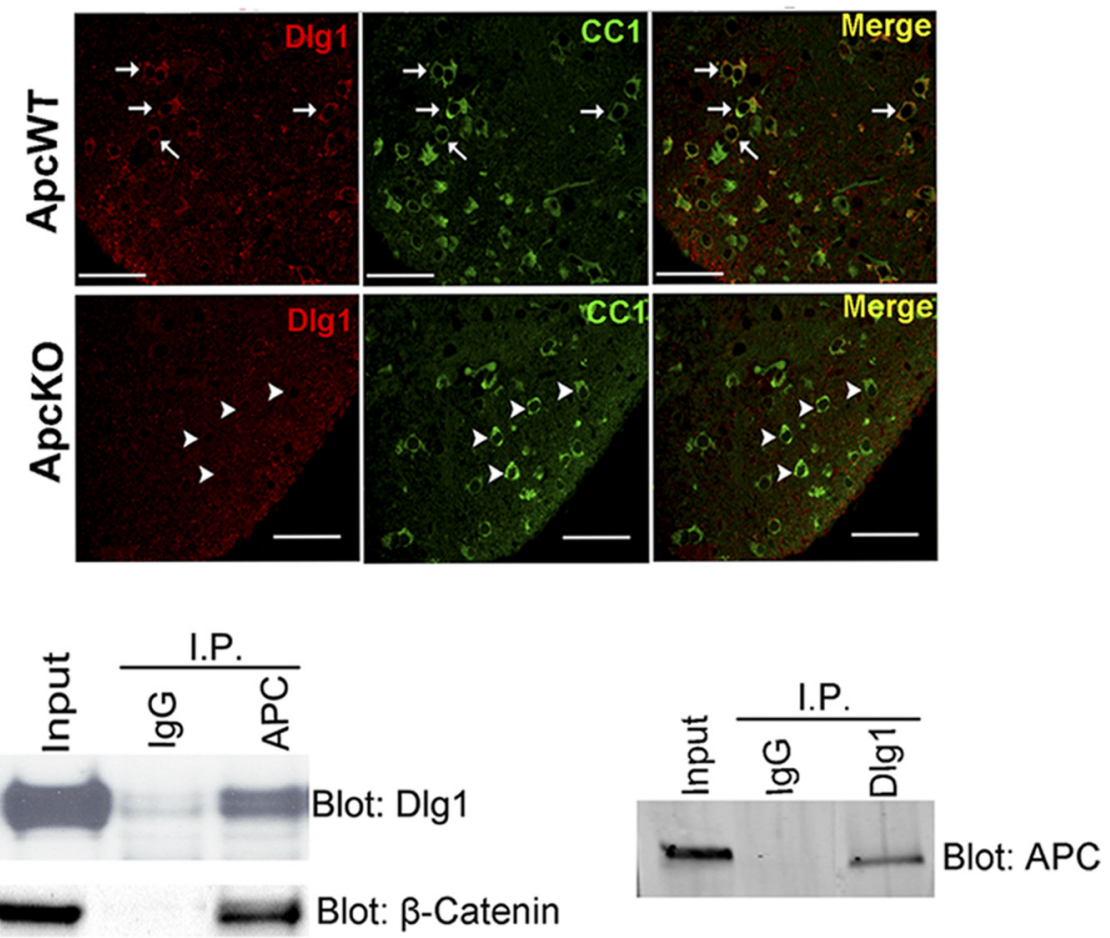

Figure 9. Genes with altered expression derived from microarray data analysis and their validations. $A$, Representative top 24 genes with altered expression upon $A p c$ ablation (red, upregulated in $A p\left(\mathrm{KO}\right.$ ) mediated by 0 lig2-Cre-ER ${ }^{\mathrm{T2}}$ with tamoxifen treatment at P6 and P7 and analysis at P14. B, Comparison and validation of microarray profile dysregulated genes by qRT-PCR. C, To provide validation at the protein level, double IHC showing that DLG1 protein expression was barely detectable in $\mathrm{CC}^{+}{ }^{+}$oligodendrocytes in P14 Apc-KO (OCE/Apc ${ }^{\mathrm{f} / \mathrm{fl}}$ ) (arrowheads), whereas there was robust expression in WT mice (Apc ${ }^{\mathrm{fl} / f l}$ ) (arrows). Tamoxifen was injected at P6 and P7. D, Coimmunoprecipitation indicating APC and DLG1 physically interact with each other, with $\beta$-catenin as a positive control, using protein extracted from day $2 \mathrm{OPC}$ cultures. Scale bars, $50 \mu \mathrm{m}$.

qRT-PCR to verify the microarray data by quantifying the expression levels of genes that were upregulated (Fig. 9B, red) and downregulated (Fig. 9B, black) in $A p c \mathrm{KO}$ mice, and the genes with both most-marked (Fig. $9 B$, Casr) and least-marked changes (Fig. 9B, Cx3cl1). Our results showed that all the qRT-PCR data were consistent with those from the microarray analysis (Fig. 9B), thus supporting the validity of the microarray profiling data.
We next used the DAVID program (Huang da et al., 2009b,c) to explore the potential functions and pathways affected by oligodendroglial Apc ablation. The analysis showed that oligodendrocyte differentiation, regulation of Wnt receptor signaling and cell proliferation were significantly enriched when these 336 altered genes were queried against the mouse GO database (Table 1), which is consistent with our data showing that $A p c$ disruption 
Table 1. Representative biological processes of gene ontology that are enriched among the altered gene expression by Apc gene disruption analyzed by DAVID program

\begin{tabular}{lcll}
\hline $\begin{array}{l}\text { Terms of biological processes } \\
\text { Oligodendrocyte differentiation }\end{array}$ & $\begin{array}{l}\text { Gene } \\
\text { count }\end{array}$ & $\begin{array}{l}p \\
\text { value }\end{array}$ & $\begin{array}{l}\text { Fold } \\
\text { enriched }\end{array}$ \\
$\begin{array}{l}\text { Negative regulation of microtubule polymerization or } \\
\quad \text { depolymerization }\end{array}$ & 3 & 0.0036 & 12.7 \\
Myelination & & 0.0254 & 11.9 \\
Axon ensheathment & 5 & 0.0026 & 8.6 \\
Negative regulation of cytoskeleton organization & 5 & 0.0031 & 7.1 \\
Regulation of Wnt receptor signaling pathway & 5 & 0.0067 & 6.6 \\
Regulation of actin polymerization or depolymerization & 4 & 0.0229 & 6.5 \\
Regulation of actin filament length & 5 & 0.0077 & 6.3 \\
Actin filament organization & 5 & 0.0083 & 6.2 \\
Regulation of actin filament polymerization & 5 & 0.0114 & 5.7 \\
Glial cell differentiation & 4 & 0.0333 & 5.6 \\
Regulation of actin filament-based process & 4 & 0.0392 & 5.3 \\
Regulation of cytoskeleton organization & 5 & 0.0153 & 5.2 \\
Regulation of cell migration & 8 & 0.0009 & 5.1 \\
Actin filament-based process & 7 & 0.0032 & 4.8 \\
Actin cytoskeleton organization & 11 & 0.0005 & 4.0 \\
Negative regulation of cell differentiation & 10 & 0.0012 & 3.8 \\
Positive regulation of cell proliferation & 10 & 0.0023 & 3.5 \\
Cell proliferation & 12 & 0.0052 & 2.7 \\
Cytoskeleton organization & 10 & 0.0160 & 2.6 \\
Regulation of cell proliferation & 13 & 0.0054 & 2.5 \\
Cell adhesion & 18 & 0.0048 & 2.1 \\
\hline & 17 & 0.0154 & 1.9 \\
\hline
\end{tabular}

Microarray analysis was used to identify 336 genes with FDR-corrected $p$ value $<0.05$ and with 1.2 -fold change cutoff. Note that oligodendrocyte differentiation and myelination, Wnt signaling pathway, and cytoskeleton regulation were significantly enriched as a result of oligodendroglial Apc disruption.

affects oligodendrocyte differentiation, proliferation, and Wnt signaling (Figs. 2-5). Interestingly, we also found that regulation of the cytoskeleton was significantly enriched upon Apc disruption (Table 1), suggesting that APC regulates oligodendrocyte differentiation by additionally controlling cytoskeleton structure (Näthke, 2006). Of note, one of the altered genes derived from microarray data analysis and verified by qRT-PCR and IHC was Dlg1 (Fig. 9B) (Chung, 2011). Previous studies reported that physical interaction between scaffolding protein DLG1 [Discs large homolog 1, also termed synapse-associated protein 97 (SAP97)] and APC is required for polarization of the microtubule cytoskeleton in astrocytes (Etienne-Manneville et al., 2005; Näthke, 2006). Our data showed that DLG1 is also expressed in oligodendrocytes, and that DLG1-immunoreactive signals were markedly decreased in the $\mathrm{CC}^{+}$oligodendrocytes of Apc KO spinal cord (Fig. 9C, arrowheads) compared with their extensive colocalization in WT mice (Fig. 9C, arrows). Coimmunoprecipitation demonstrated that APC physically interacted with DLG1 in oligodendrocytes, in addition to binding $\beta$-catenin (Fig. 9D). Our results suggest that the APC binding partner DLG1 regulates oligodendrocyte differentiation, possibly via modulation of the oligodendroglial cytoskeleton, but further studies are needed to define its role in oligodendroglial lineage cells.

\section{OPCs develop fewer and shorter processes in Apc deletion mice}

APC stabilizes the microtubule cytoskeleton (Näthke, 2006), which is critical for process extension (Lunn et al., 1997; Bauer et al., 2009). There are two pools of microtubules: dynamic microtubules and stabilized microtubules (Saxton et al., 1984; Schulze and Kirschner, 1987). Acetylated $\alpha$-tubulin is a marker of stabilized microtubules (Bloom, 2004; Yokota et al., 2009). We showed that $\alpha$-tubulin and acetylated $\alpha$-tubulin were colabeled with $\mathrm{APC}^{+}$cell bodies and processes (Fig. 10 A,B) in our culture system, a similar microtubule pattern obtained from $\beta$-tubulin (Lunn et al., 1997). Using primary OPC cultures, we found that the ratio of acetylated $\alpha$-tubulin to total $\alpha$-tubulin increased upon OPC differentiation into oligodendrocytes (Fig. 10C,D), indicating a role of microtubule stabilization during OPC differentiation. Unfortunately, unlike cultured OPCs with dominant active $\beta$-catenin (Fancy et al., 2009; Feigenson et al., 2009; Ye et al., 2009), cultured Apc-ablated OPCs did not survive well (data not shown); this precluded in vitro analysis of process extension by Apc-deficient OPCs.

In vivo, OPCs undergo a morphological transition from a few simple processes to a complex process meshwork. We hypothesized that disruption of Apc would affect adult OPC process extension, an event that requires microtubule stability. In the spinal cord of adult OCE $/ A p c^{\mathrm{f} / / \mathrm{t}}$, EYFP mice (tamoxifen treatment at P6 and P7), there was a mosaic pattern of OPCs: EYFP-negative $A p c$-WT OPCs and EYFP-positive Apc-deficient OPCs (Fig. $10 E, F)$ due to incomplete Cre-mediated recombination. We used Sholl analysis (Rajasekharan et al., 2009) (see Materials and Methods) to quantify and compare the number and length of process branches of individual OPCs (Fig. 10G). Our data showed that Apc-KO $\left(\mathrm{EYFP}^{+}\right)$OPCs extended shorter and less complex processes compared with Apc-WT $\left(\mathrm{EYFP}^{-}\right.$) OPCs (Fig. $10 H$ ), indicating that APC might regulate the formation of the complex process network of OPCs. Alternatively, since our data showed that $A p c$ ablation inhibited OPC differentiation, the lesser complexity of OPC processes could also possibly result from the blockage of OPC differentiation at some step before complex process formation.

\section{Discussion}

\section{Transient APC expression in oligodendroglial lineage cells}

Double IHC using APC antibody and CC1 displayed completely nonoverlapping staining patterns in the adult neocortex (Fig. $1 C$ ), arguing strongly against the equivalence of APC with oligodendrocyte marker CC1. One of the interesting findings in our study is that APC is transiently expressed in oligodendroglial lineage cells during normal myelination and again during remyelination after CNS injury (Fig. 1). Immunoreactive APC was very low in OPCs but transiently upregulated in myelinating oligodendrocytes. We also demonstrated that APC and the Wntsignaling effector Tcf7l2 were transiently and dynamically expressed in the same population of oligodendrocytes (Fig. $1 K$ ). A previous study showed that activity of the Wnt $/ \beta$-catenin pathway increased after lysolecithin-induced demyelination, as evidenced by elevated expression of Tcf7l2 (Fancy et al., 2009). Since canonical Wnt $/ \beta$-catenin signaling proceeds via Tcf7l2 to initiate transcriptional activity in oligodendroglial lineage cells (Fancy et al., 2009), the overlapping patterns of APC and Tcf7l2 (Fig. $1 K$ ) suggest that activation of $\mathrm{Wnt} / \beta$-catenin signaling after lysolecithin-induced demyelination (Fancy et al., 2009) occurs in $\mathrm{APC}^{+}$cells, and argues for the existence of a tightly regulated, negative feedback of APC and Wnt $/ \beta$-catenin signaling during oligodendrocyte differentiation. Indeed, we observed completely overlapping patterns of APC and Tcf712 reinduction in both cuprizone-induced and MOG-peptide-induced demyelinative models (our unpublished data).

In the present study, genetic $A p c$ ablation was initiated either by constitutive cre transgenes, or by activation of an inducible cre transgene at the end of the first postnatal week; thus, initial Apc recombination took place largely in OPCs, rather than in oligo- 

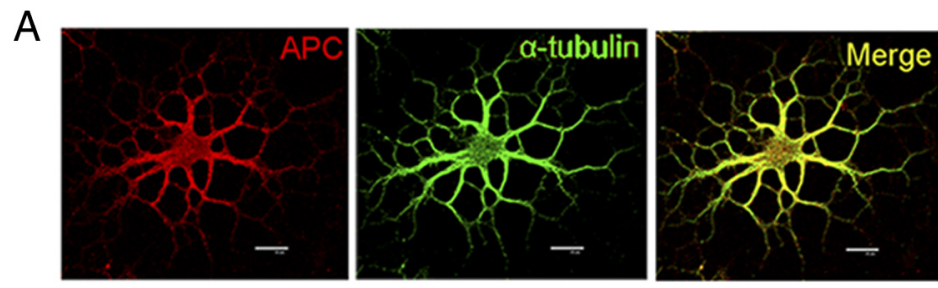

B

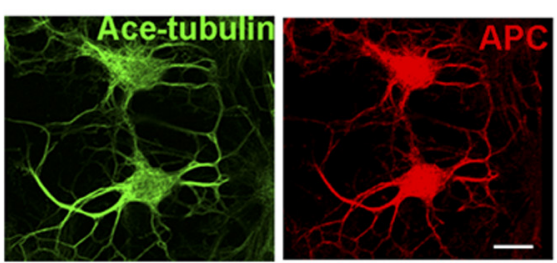

C
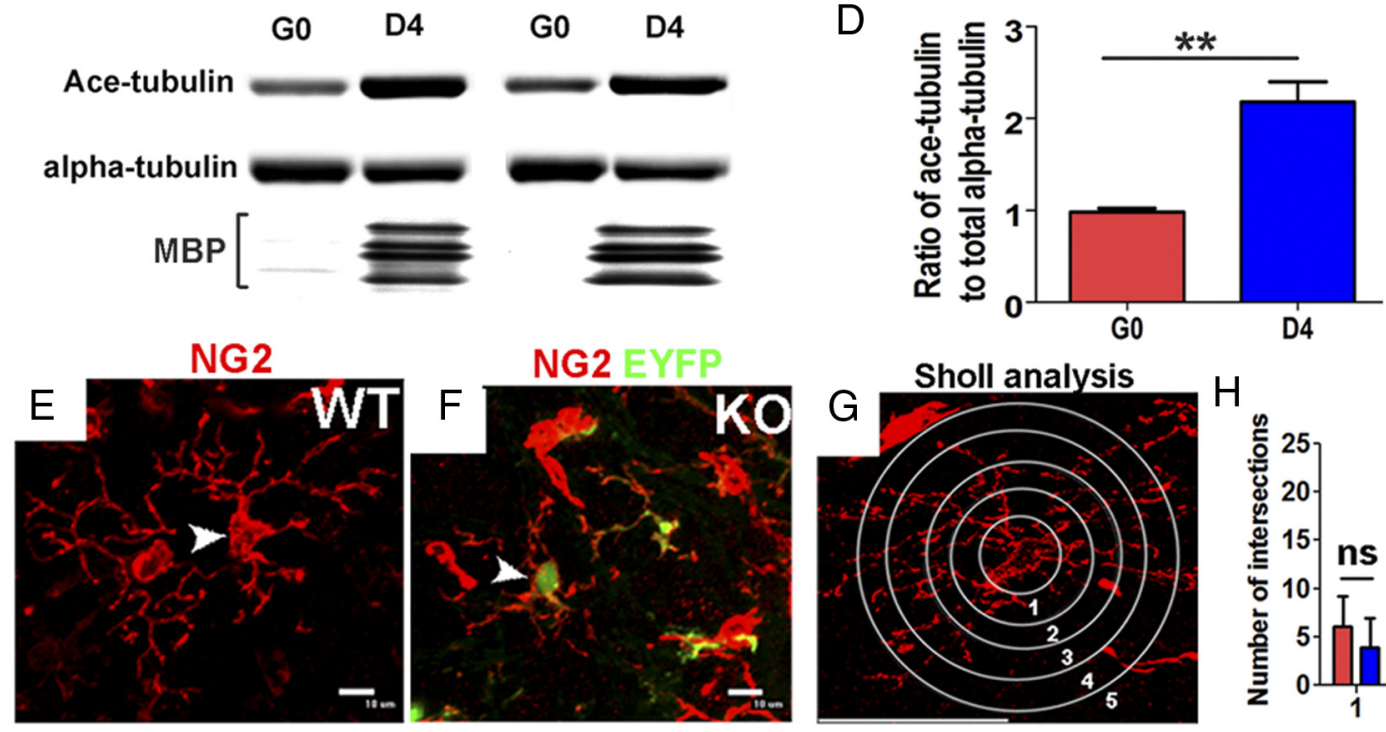

D4

Figure 10. Apc disruption affects the morphological complexity of OPCs and localizes to stable microtubules in oligodendrocytes. $\boldsymbol{A}, \boldsymbol{B}$, Immunostaining of APC, $\alpha$-tubulin, and acetylated $\alpha$-tubulin on cultured oligodendrocytes with $2 \mathrm{~d}$ differentiation. C, D, Western blot of total $\alpha$-tubulin and acetylated $\alpha$-tubulin in OPCS (GO) and oligodendrocytes at $4 \mathrm{~d}$ differentiation (D4) and quantification. $\boldsymbol{E}-\boldsymbol{H}$, Sholl analysis $(\boldsymbol{G})$ on the process complexity and branching of EYFP ${ }^{-} / \mathrm{NG2}{ }^{+} A p c$-intact $\mathrm{OPC}(\boldsymbol{E})$ and EYFP ${ }^{+} / \mathrm{NG}^{+}{ }^{+} \mathrm{Apc}$-deficient $\mathrm{OPCs}(\boldsymbol{F})$ in the spinal cord of P40 OCE, $A p c^{\mathrm{fl} / f \mathrm{l}}$, EYFP mice (tamoxifen injection at P6 and P7) and quantification of intersection numbers at each radius $(1-5)\left(\boldsymbol{H}, \geq 30 \mathrm{OPC}\right.$ each group from 4 adult $0 \mathrm{CE}, A p c^{\mathrm{fl} / \mathrm{fl}}$ mice with tamoxifen treatment at P6, P7). Scale bars, $10 \mu \mathrm{m}$.

dendroglia. In future studies, we plan also to ablate $A p c$ at later time points to determine the effects of APC deficiency in differentiated oligodendroglia on myelination and remyelination.

Wnt/ $\beta$-catenin signaling and oligodendrocyte differentiation in $A p c^{\mathrm{min} /+}$ mice

Though a prior publication speculated that $\mathrm{Wnt} / \beta$-catenin signaling is overactivated in $A p c^{\mathrm{min} /+}$ mice (Fancy et al., 2009), we found that both conditional $\mathrm{KO}$ of one-allele $A p c$ (OCE/Apc $c^{\mathrm{f} /}+$ mice) (Fig. 5D-G) and nonsense one-allele truncated mutation of $A p c$ ( $A p c^{\mathrm{min} /+}$ mice) (Fig. $\left.6 A-C\right)$ have similar levels of Wnt/ $\beta$ catenin signaling to those in WT mice. These results argue against the assumption that canonical Wnt/ $\beta$-catenin signaling is dysregulated in $A p c^{\mathrm{min} /+}$ mice. We also found that postnatal oligodendrocyte development is normal in $A p c^{\mathrm{min} /+}$ mice (Fig. $6 D-G$ ). These data suggest that the delayed oligodendroglial differentiation observed in $A p c^{\mathrm{min} /+}$ mice with lysolecithin-induced demyelinative injury (Fancy et al., 2009) probably results from a Wnt/ $\beta$-catenin-independent effect of monoallelic Apc truncation or deletion in an injury-specific manner.

\section{$\beta$-Catenin disruption does not affect oligodendrocyte differentiation in early postnatal or adult mice}

Prior data obtained from dominant activation of oligodendroglial lineage $\beta$-catenin suggested that canonical $\mathrm{Wnt} / \beta$-catenin signaling inhibits early postnatal oligodendrocyte differentiation (Fancy et al., 2009; Feigenson et al., 2009; Ye et al., 2009). However, those reports did not conclusively address whether $\beta$-catenin is important in oligodendrocyte differentiation under physiological conditions, since dominant active $\beta$-catenin may affect signaling pathways or target genes not normally controlled by $\beta$-catenin-mediated Wnt signaling. In support of this caveat, $\beta$-catenin deletion does not affect hematopoiesis and lymphopoiesis (Cobas et al., 2004; Prlic and Bevan, 2011), although dominant activation of $\beta$-catenin suggests the opposite (Gounari et al., 2001).

Thus far, the best documented evidence for modulation of development of the oligodendroglial lineage by physiological $\beta$-catenin-mediated Wnt signaling was obtained by $\beta$-catenin loss of function (Ye et al., 2009) and manipulation of Wnt ligands (Langseth et al., 2010) in the embryo. These studies conclusively showed that Wnt/ $\beta$-catenin signaling is important in the generation of OPCs from embryonic neural stem cells (Ye et al., 2009; Langseth et al., 2010). Using the same breeding paradigm as the one in a previous study (Ye et al., 2009), we showed that oligodendrocyte differentiation was similar in Cnp-Cre/Ctnnb $1^{\mathrm{fl} / \mathrm{fl}}$ neonates to that in $C t n n b 1^{\mathrm{fl} / \mathrm{fl}}$ controls (Fig. $7 \mathrm{~K}$ ). This observation was further supported by the results we obtained by $\beta$-catenin loss of function mediated by constitutive NG2-Cre (Fig. 7A-G) or inducible Olig2-Cre-ER ${ }^{\mathrm{T} 2}$ (Fig. $7 \mathrm{H}-\mathrm{J}$ ). Our data suggest that, though important in embryonic OPC generation, $\beta$-catenin is dispensable for postnatal oligodendrocyte differentiation under physiological conditions. Nevertheless, this does not preclude the possibility that manipulation of oligodendroglial Wnt signaling might promote oligodendrocyte remyelination under injury conditions, as suggested by a recent study (Fancy et al., 2011). It has been reported that $\gamma$-catenin (plakoglobin) can compensate for the loss of $\beta$-catenin in cardiomyocytes (Zhou et al., 2007) and 
hepatocytes (Wickline et al., 2011). Whether this compensatory mechanism applies to CNS oligodendroglial lineage cells needs to be determined.

\section{Role of APC in oligodendrocyte development: $\beta$-catenin- dependent and $\boldsymbol{\beta}$-catenin-independent mechanisms}

The transient expression of APC suggests its role in oligodendroglial differentiation and myelination. To elucidate this role under physiological conditions, we used Cre-LoxP-mediated Apc loss of function specifically in oligodendroglial lineage cells. We found that $A p c$ deletion inhibits oligodendrocyte differentiation and myelination (Fig. 2), and that this inhibition persists into adult oligodendroglial lineage cells (Fig. 4), suggesting that APC is critical in oligodendroglial development.

Why does Apc disruption inhibit oligodendrocyte differentiation? One of the mechanisms responsible for this effect is the elevation of canonical Wnt $/ \beta$-catenin signaling. In the colorectal cancer research field, it is well established that APC negatively regulates canonical $\beta$-catenin-mediated Wnt signaling by targeting $\beta$-catenin for subsequent proteasome-mediated degradation (Näthke, 2006). According to this well established concept, we postulate and present compelling data to show that $A p c$ loss of function results in dysregulation of oligodendroglial Wnt $/ \beta$ catenin signaling (Fig. 5), which has previously been shown to affect early postnatal oligodendrocyte differentiation (Fancy et al., 2009; Feigenson et al., 2009; Ye et al., 2009).

Another interesting finding of our study is that $A p c$ ablation reduced OPC proliferation (Fig. 3). Overactivation of Wnt $/ \beta$ catenin signaling inhibits oligodendrocyte differentiation but does not perturb proliferation (Fancy et al., 2009). If the effects of $A p c$ deletion on the oligodendroglial lineage were due solely to overactivation of Wnt/ $\beta$-catenin signaling, we would not expect to observe a decrease in OPC proliferation in $A p c \mathrm{KO}$ mice. Our observation of a reduced rate of OPC proliferation in homozygous $A p c \mathrm{KO}$ mice is reminiscent of the slowed proliferation of Apc-deficient radial glia demonstrated in a prior study and ascribed to abnormal organization of microtubules in mitotic spindles (Yokota et al., 2009). Furthermore, the inhibition of oligodendrocyte differentiation and myelination persists in the adult CNS (Fig. 4), a phenotype that is different from that in dominant active $\beta$-catenin transgenic mice, in which oligodendrocyte differentiation is normal in the adult (Fancy et al., 2009). These phenotypic discrepancies between $A p c \mathrm{KO}$ and $\beta$-catenin stabilization suggest an additional, $\beta$-catenin-independent role of APC in regulating oligodendrocyte differentiation. To prove the existence of this $\beta$-catenin-independent role of APC in oligodendrocytes, we conditionally ablated $A p c$ and Ctnnb1 genes simultaneously. Since our data showed that loss of function of $\beta$-catenin does not affect oligodendrocyte differentiation (Fig. 7), the inhibition of oligodendrocyte differentiation in $A p c$ and Ctnnb1 dKO mice (Fig. 8) indicates that APC regulates oligodendrocyte differentiation via an additional novel $\beta$-cateninindependent mechanism.

What pathway accounts for this $\beta$-catenin-independent mechanism of APC? We explored this issue by GO analysis of a list, derived from microarray data, of 336 genes with altered expression upon $A p c$ deletion. As a positive control to validate the efficacy of GO analysis, oligodendrocyte differentiation, and myelination, Wnt signaling and cell proliferation were all significantly enriched upon Apc deletion (Table 1), which is in line with APC's Wnt $/ \beta$-catenin signaling modulation (Aoki and Taketo, 2007) and also with the data from our current study (Figs. 2-5). We also found that the biological process of GO, termed regula- tion cytoskeleton stability, was significantly enriched (Table 1), which suggests that APC's regulation of cytoskeleton stability might be one of the $\beta$-catenin-independent mechanisms, although we cannot exclude the possibility that this dysregulation of cytoskeletal stability could also result from $\beta$-cateninmediated Wnt-signaling overactivation. Using an in vitro culture system, we showed that the stabilized microtubule component, acetylated $\alpha$-tubulin (Fig. 10B) (Shintani et al., 2009), was significantly increased upon OPC differentiation (Fig. 10C,D), a result consistent with our in vivo observation that Apc-deficient OPCs developed less and shorter process branching (Fig. 10H), an event in which microtubule stability plays an important role (Bauer et al., 2009). Nevertheless, more studies are needed to investigate how APC modulates microtubule cytoskeleton stability and regulates oligodendrocyte differentiation by controlling process extension.

In conclusion, our study shows that APC is expressed transiently in the oligodendroglial lineage cells during normal oligodendrocyte development and during oligodendrocyte regeneration. Loss-of-function experiments suggest that APC regulates oligodendrocyte differentiation via both $\beta$-catenindependent and novel $\beta$-catenin-independent mechanisms. In addition, our findings have revealed that $\beta$-catenin is dispensable for postnatal oligodendrocyte differentiation under physiological conditions, and that $A p c$ one-allele deficiency is not sufficient to dysregulate $\beta$-catenin-mediated Wnt signaling in oligodendroglial lineage cells.

\section{References}

Aoki K, Taketo MM (2007) Adenomatous polyposis coli (APC): a multifunctional tumor suppressor gene. J Cell Sci 120:3327-3335. CrossRef Medline

Baldin V, Lukas J, Marcote MJ, Pagano M, Draetta G (1993) Cyclin D1 is a nuclear protein required for cell cycle progression in G1. Genes Dev 7:812-821. CrossRef Medline

Barres BA, Raff MC (1999) Axonal control of oligodendrocyte development. J Cell Biol 147:1123-1128. CrossRef Medline

Bauer NG, Richter-Landsberg C, Ffrench-Constant C (2009) Role of the oligodendroglial cytoskeleton in differentiation and myelination. Glia 57: 1691-1705. CrossRef Medline

Bhat RV, Baraban JM, Johnson RC, Eipper BA, Mains RE (1994) High levels of expression of the tumor suppressor gene APC during development of the rat central nervous system. J Neurosci 14:3059-3071. Medline

Bhat RV, Axt KJ, Fosnaugh JS, Smith KJ, Johnson KA, Hill DE, Kinzler KW, Baraban JM (1996) Expression of the APC tumor suppressor protein in oligodendroglia. Glia 17:169-174. CrossRef Medline

Bloom K (2004) Microtubule composition: cryptography of dynamic polymers. Proc Natl Acad Sci U S A 101:6839-6840. CrossRef Medline

Brakeman JS, Gu SH, Wang XB, Dolin G, Baraban JM (1999) Neuronal localization of the adenomatous polyposis coli tumor suppressor protein. Neuroscience 91:661-672. CrossRef Medline

Brault V, Moore R, Kutsch S, Ishibashi M, Rowitch DH, McMahon AP, Sommer L, Boussadia O, Kemler R (2001) Inactivation of the betacatenin gene by Wnt1-Cre-mediated deletion results in dramatic brain malformation and failure of craniofacial development. Development 128: 1253-1264. Medline

Chen Y, Tian X, Kim WY, Snider WD (2011) Adenomatous polyposis coli regulates axon arborization and cytoskeleton organization via its N-terminus. PLoS One 6:e24335. CrossRef Medline

Chew LJ, Shen W, Ming X, Senatorov VV Jr, Chen HL, Cheng Y, Hong E, Knoblach S, Gallo V (2011) SRY-box containing gene 17 regulates the $\mathrm{Wnt} / \beta$-catenin signaling pathway in oligodendrocyte progenitor cells. J Neurosci 31:13921-13935. CrossRef Medline

Chung AY, Kim S, Kim H, Bae YK, Park HC (2011) Microarray screening for genes involved in oligodendrocyte differentiation in the zebrafish CNS. Exp Neurobiol 20:85-91. CrossRef Medline

Cobas M, Wilson A, Ernst B, Mancini SJ, MacDonald HR, Kemler R, Radtke 
F (2004) Beta-catenin is dispensable for hematopoiesis and lymphopoiesis. J Exp Med 199:221-229. CrossRef Medline

Etienne-Manneville S, Manneville JB, Nicholls S, Ferenczi MA, Hall A (2005) Cdc42 and Par6-PKCzeta regulate the spatially localized association of Dlg1 and APC to control cell polarization. J Cell Biol 170:895-901. CrossRef Medline

Fancy SP, Baranzini SE, Zhao C, Yuk DI, Irvine KA, Kaing S, Sanai N, Franklin RJ, Rowitch DH (2009) Dysregulation of the Wnt pathway inhibits timely myelination and remyelination in the mammalian CNS. Genes Dev 23:1571-1585. CrossRef Medline

Fancy SP, Harrington EP, Yuen TJ, Silbereis JC, Zhao C, Baranzini SE, Bruce CC, Otero JJ, Huang EJ, Nusse R, Franklin RJ, Rowitch DH (2011) Axin2 as regulatory and therapeutic target in newborn brain injury and remyelination. Nat Neurosci 14:1009-1016. CrossRef Medline

Feigenson K, Reid M, See J, Crenshaw EB 3rd, Grinspan JB (2009) Wnt signaling is sufficient to perturb oligodendrocyte maturation. Mol Cell Neurosci 42:255-265. CrossRef Medline

Gounari F, Aifantis I, Khazaie K, Hoeflinger S, Harada N, Taketo MM, von Boehmer H (2001) Somatic activation of beta-catenin bypasses preTCR signaling and TCR selection in thymocyte development. Nat Immunol 2:863-869. CrossRef Medline

Gounari F, Chang R, Cowan J, Guo Z, Dose M, Gounaris E, Khazaie K (2005) Loss of adenomatous polyposis coli gene function disrupts thymic development. Nat Immunol 6:800-809. CrossRef Medline

Guo F, Ma J, McCauley E, Bannerman P, Pleasure D (2009) Early postnatal proteolipid promoter-expressing progenitors produce multilineage cells in vivo. J Neurosci 29:7256-7270. CrossRef Medline

Guo F, Maeda Y, Ma J, Xu J, Horiuchi M, Miers L, Vaccarino F, Pleasure D (2010) Pyramidal neurons are generated from oligodendroglial progenitor cells in adult piriform cortex. J Neurosci 30:12036-12049. CrossRef Medline

Guo F, Maeda Y, Ma J, Delgado M, Sohn J, Miers L, Ko EM, Bannerman P, Xu J, Wang Y, Zhou C, Takebayashi H, Pleasure D (2011) Macroglial plasticity and the origins of reactive astroglia in experimental autoimmune encephalomyelitis. J Neurosci 31:11914-11928. CrossRef Medline

Guo F, Maeda Y, Ko EM, Delgado M, Horiuchi M, Soulika A, Miers L, Burns T, Itoh T, Shen H, Lee E, Sohn J, Pleasure D (2012) Disruption of NMDA receptors in oligodendroglial lineage cells does not alter their susceptibility to experimental autoimmune encephalomyelitis or their normal development. J Neurosci 32:639-645. CrossRef Medline

Horiuchi M, Lindsten T, Pleasure D, Itoh T (2010) Differing in vitro survival dependency of mouse and rat NG2+ oligodendroglial progenitor cells. J Neurosci Res 88:957-970. Medline

Huang da W, Sherman BT, Lempicki RA (2009a) Bioinformatics enrichment tools: paths toward the comprehensive functional analysis of large gene lists. Nucleic Acids Res 37:1-13. CrossRef Medline

Huang da W, Sherman BT, Lempicki RA (2009b) Systematic and integrative analysis of large gene lists using DAVID bioinformatics resources. Nat Protoc 4:44-57. CrossRef Medline

Huang da W, Sherman BT, Zheng X, Yang J, Imamichi T, Stephens R, Lempicki RA (2009c) Extracting biological meaning from large gene lists with DAVID. Curr Protoc Bioinformatics Chapter 13:Unit 13.11. CrossRef Medline

Imura T, Wang X, Noda T, Sofroniew MV, Fushiki S (2010) Adenomatous polyposis coli is essential for both neuronal differentiation and maintenance of adult neural stem cells in subventricular zone and hippocampus. Stem Cells 28:2053-2064. CrossRef Medline

Itoh T, Beesley J, Itoh A, Cohen AS, Kavanaugh B, Coulter DA, Grinspan JB, Pleasure D (2002) AMPA glutamate receptor-mediated calcium signaling is transiently enhanced during development of oligodendrocytes. J Neurochem 81:390-402. CrossRef Medline

Jimbo T, Kawasaki Y, Koyama R, Sato R, Takada S, Haraguchi K, Akiyama T (2002) Identification of a link between the tumour suppressor APC and the kinesin superfamily. Nat Cell Biol 4:323-327. CrossRef Medline

Kipp M, Clarner T, Dang J, Copray S, Beyer C (2009) The cuprizone animal model: new insights into an old story. Acta Neuropathol 118:723-736. CrossRef Medline

Kuraguchi M, Wang XP, Bronson RT, Rothenberg R, Ohene-Baah NY, Lund JJ, Kucherlapati M, Maas RL, Kucherlapati R (2006) Adenomatous polyposis coli (APC) is required for normal development of skin and thymus. PLoS Genet 2:e146. CrossRef Medline

Langseth AJ, Munji RN, Choe Y, Huynh T, Pozniak CD, Pleasure SJ (2010)
Wnts influence the timing and efficiency of oligodendrocyte precursor cell generation in the telencephalon. J Neurosci 30:13367-13372. CrossRef Medline

Lappe-Siefke C, Goebbels S, Gravel M, Nicksch E, Lee J, Braun PE, Griffiths IR, Nave KA (2003) Disruption of Cnp1 uncouples oligodendroglial functions in axonal support and myelination. Nat Genet 33:366-374. CrossRef Medline

Li A, Xing Y, Chan B, Heisterkamp N, Groffen J, Borok Z, Minoo P, Li C (2010) Cell type-specific expression of adenomatous polyposis coli in lung development, injury, and repair. Dev Dyn 239:2288-2297. CrossRef Medline

Lunn KF, Baas PW, Duncan ID (1997) Microtubule organization and stability in the oligodendrocyte. J Neurosci 17:4921-4932. Medline

Maretto S, Cordenonsi M, Dupont S, Braghetta P, Broccoli V, Hassan AB, Volpin D, Bressan GM, Piccolo S (2003) Mapping Wnt/beta-catenin signaling during mouse development and in colorectal tumors. Proc Natl Acad Sci U S A 100:3299-3304. CrossRef Medline

Mason JL, Toews A, Hostettler JD, Morell P, Suzuki K, Goldman JE, Matsushima GK (2004) Oligodendrocytes and progenitors become progressively depleted within chronically demyelinated lesions. Am J Pathol 164: 1673-1682. CrossRef Medline

Mili S, Moissoglu K, Macara IG (2008) Genome-wide screen reveals APCassociated RNAs enriched in cell protrusions. Nature 453:115-119. CrossRef Medline

Moser AR, Mattes EM, Dove WF, Lindstrom MJ, Haag JD, Gould MN (1993) ApcMin, a mutation in the murine Apc gene, predisposes to mammary carcinomas and focal alveolar hyperplasias. Proc Natl Acad Sci U S A 90:8977-8981. CrossRef Medline

Näthke I (2006) Cytoskeleton out of the cupboard: colon cancer and cytoskeletal changes induced by loss of APC. Nat Rev Cancer 6:967-974. CrossRef Medline

Prlic M, Bevan MJ (2011) Cutting edge: beta-catenin is dispensable for T cell effector differentiation, memory formation, and recall responses. J Immunol 187:1542-1546. CrossRef Medline

Qian Z, Chen L, Fernald AA, Williams BO, Le Beau MM (2008) A critical role for Apc in hematopoietic stem and progenitor cell survival. J Exp Med 205:2163-2175. CrossRef Medline

Rajasekharan S, Baker KA, Horn KE, Jarjour AA, Antel JP, Kennedy TE (2009) Netrin 1 and Dcc regulate oligodendrocyte process branching and membrane extension via Fyn and RhoA. Development 136:415-426. CrossRef Medline

Rivers LE, Young KM, Rizzi M, Jamen F, Psachoulia K, Wade A, Kessaris N, Richardson WD (2008) PDGFRA/NG2 glia generate myelinating oligodendrocytes and piriform projection neurons in adult mice. Nat Neurosci 11:1392-1401. CrossRef Medline

Sasaki T, Irie-Sasaki J, Horie Y, Bachmaier K, Fata JE, Li M, Suzuki A, Bouchard D, Ho A, Redston M, Gallinger S, Khokha R, Mak TW, Hawkins PT, Stephens L, Scherer SW, Tsao M, Penninger JM (2000) Colorectal carcinomas in mice lacking the catalytic subunit of PI(3)Kgamma. Nature 406:897-902. CrossRef Medline

Saxton WM, Stemple DL, Leslie RJ, Salmon ED, Zavortink M, McIntosh JR (1984) Tubulin dynamics in cultured mammalian cells. J Cell Biol 99: 2175-2186. CrossRef Medline

Schulze E, Kirschner M (1987) Dynamic and stable populations of microtubules in cells. J Cell Biol 104:277-288. CrossRef Medline

Shintani T, Ihara M, Tani S, Sakuraba J, Sakuta H, Noda M (2009) APC2 plays an essential role in axonal projections through the regulation of microtubule stability. J Neurosci 29:11628-11640. CrossRef Medline

Soulika AM, Lee E, McCauley E, Miers L, Bannerman P, Pleasure D (2009) Initiation and progression of axonopathy in experimental autoimmune encephalomyelitis. J Neurosci 29:14965-14979. CrossRef Medline

Stacey DW (2003) Cyclin D1 serves as a cell cycle regulatory switch in actively proliferating cells. Curr Opin Cell Biol 15:158-163. CrossRef Medline

Stolt CC, Rehberg S, Ader M, Lommes P, Riethmacher D, Schachner M, Bartsch U, Wegner M (2002) Terminal differentiation of myelinforming oligodendrocytes depends on the transcription factor Sox10. Genes Dev 16:165-170. CrossRef Medline

Takebayashi H, Nabeshima Y, Yoshida S, Chisaka O, Ikenaka K, Nabeshima Y (2002) The basic helix-loop-helix factor olig2 is essential for the development of motoneuron and oligodendrocyte lineages. Curr Biol 12:11571163. CrossRef Medline 
Traka M, Wollmann RL, Cerda SR, Dugas J, Barres BA, Popko B (2008) Nur7 is a nonsense mutation in the mouse aspartoacylase gene that causes spongy degeneration of the CNS. J Neurosci 28:11537-11549. CrossRef Medline

Wang X, Imura T, Sofroniew MV, Fushiki S (2011) Loss of adenomatous polyposis coli in Bergmann glia disrupts their unique architecture and leads to cell nonautonomous neurodegeneration of cerebellar Purkinje neurons. Glia 59:857-868. CrossRef Medline

Wen Y, Eng CH, Schmoranzer J, Cabrera-Poch N, Morris EJ, Chen M, Wallar BJ, Alberts AS, Gundersen GG (2004) EB1 and APC bind to mDia to stabilize microtubules downstream of Rho and promote cell migration. Nat Cell Biol 6:820-830. CrossRef Medline

Wickline ED, Awuah PK, Behari J, Ross M, Stolz DB, Monga SP (2011) Hepatocyte gamma-catenin compensates for conditionally deleted betacatenin at adherens junctions. J Hepatol 55:1256-1262. CrossRef Medline

Ye F, Chen Y, Hoang T, Montgomery RL, Zhao XH, Bu H, Hu T, Taketo MM, van Es JH, Clevers H, Hsieh J, Bassel-Duby R, Olson EN, Lu QR
(2009) HDAC1 and HDAC2 regulate oligodendrocyte differentiation by disrupting the beta-catenin-TCF interaction. Nat Neurosci 12:829 838. CrossRef Medline

Yokota Y, Kim WY, Chen Y, Wang X, Stanco A, Komuro Y, Snider W, Anton ES (2009) The adenomatous polyposis coli protein is an essential regulator of radial glial polarity and construction of the cerebral cortex. Neuron 61:42-56. CrossRef Medline

Zhou FQ, Zhou J, Dedhar S, Wu YH, Snider WD (2004) NGF-induced axon growth is mediated by localized inactivation of GSK-3beta and functions of the microtubule plus end binding protein APC. Neuron 42:897-912. CrossRef Medline

Zhou J, Qu J, Yi XP, Graber K, Huber L, Wang X, Gerdes AM, Li F (2007) Upregulation of gamma-catenin compensates for the loss of betacatenin in adult cardiomyocytes. Am J Physiol Heart Circ Physiol 292:H270-H276. Medline

Zhu X, Bergles DE, Nishiyama A (2008) NG2 cells generate both oligodendrocytes and gray matter astrocytes. Development 135:145-157. Medline 